\title{
Interest rate reaction functions for the euro area Evidence from panel data analysis
}

Karsten Ruth

(Goethe-University Frankfurt)

Discussion Paper

Series 1: Studies of the Economic Research Centre No 33/2004 
Editorial Board:

Heinz Herrmann

Thilo Liebig

Karl-Heinz Tödter

Deutsche Bundesbank, Wilhelm-Epstein-Strasse 14, 60431 Frankfurt am Main, Postfach 1006 02, 60006 Frankfurt am Main

Tel +49 69 9566-1

Telex within Germany 41227, telex from abroad 414431, fax +49695601071

Please address all orders in writing to: Deutsche Bundesbank,

Press and Public Relations Division, at the above address or via fax No +49 69 9566-3077

Reproduction permitted only if source is stated.

ISBN 3-86558-027-0 


\begin{abstract}
As of today, estimating interest rate reaction functions for the Euro Area is hampered by the short time span since the conduct of a single monetary policy. In this paper we circumvent the common use of aggregated data before 1999 by estimating interest rate reaction functions based on a panel including actual EMU Member States. We find that exploiting the cross-section dimension of a multi-country panel and accounting for cross-country heterogeneity in advance of the single monetary policy pays off with regard to the estimated reaction functions' ability to describe actual interest rate dynamics. We retrieve a panel reaction function which is demonstrated to be a valuable tool for evaluating episodes of monetary policy since 1999 .
\end{abstract}

Keywords: Monetary Policy, Reaction Function, Euro Area, Panel Data JEL Classification: E43, E58, C33 


\section{Non-Technical Summary}

Estimating monetary policy reaction functions for the Euro Area has gained renewed interest in academic research with Stage Three of the EMU. However, as of today, estimating interest rate reaction functions for the European Central Bank (ECB) is still hampered by the lack of sufficiently long area-wide time series since 1999 .

This is why it is common in the literature to use aggregated, "synthetic" time series for estimating reaction functions for the Euro Area. These reaction functions are typically evaluated out-of-sample in order to assess their ability to describe interest rate setting since 1999.

In this paper we circumvent the common use of "synthetic" data by estimating interest rate reaction functions based on a panel including actual Member States of the EMU. Applying panel techniques to country-specific data before 1999, we account for cross-country heterogeneity in advance of the single monetary policy. Moreover, by exploiting the cross-section dimension of a multi-country panel it is possible to shorten the estimation sample. Excluding data from the eighties and starting with estimation in 1993 (after the signing of the Maastricht Treaty) we avoid to base our analysis on a period when monetary policy in most of the European countries was severely restricted by the Exchange Rate Mechanism (ERM).

We find that estimating interest rate reaction functions within a panel framework pays off with regard to predicting short-term nominal interest rates since 1999. In particular, accounting for heterogeneous adjustment and short-run dynamics improves the predictive ability of the estimated error-correction equations compared to alternative equations estimated with aggregated data.

Finally, we demonstrate that the preferred panel reaction function might be a valuable tool for evaluating episodes of monetary policy since 1999. 


\section{Nicht-technische Zusammenfassung}

Die Schätzung geldpolitischer Reaktionsfunktionen hat mit der Einführung einer gemeinsamen europäischen Geldpolitik erneut an Bedeutung gewonnen. Die empirische Ermittlung einer Zinsregel zur Beschreibung des geldpolitischen Handelns der Europäischen Zentralbank wird jedoch nach wie vor durch die geringe Anzahl von Beobachtungen für gesamteuropäische Zeitreihen seit 1999 erschwert.

Üblicherweise wird diesem Problem durch die Verwendung aggregierter, „synthetischer" Zeitreihen vor 1999 begegnet. Dabei werden auf der Grundlage gewichteter Durchschnitte länderspezifischer Zeitreihen Reaktionsfunktionen geschätzt und deren Erklärungskraft für die Zinsentwicklung nach 1999 im Rahmen einer Out-of-SampleEvaluation überprüft.

Ziel dieses Papiers ist die Vorstellung eines Panel-Ansatzes zur Schätzung gesamteuropäischer Reaktionsfunktionen auf Grundlage von Länderdaten vor 1999. Im Gegensatz zur Verwendung aggregierter Zeitreihen erlaubt die Anwendung von PanelSchätztechniken, Heterogenität zwischen den Ländern im Vorfeld einer gemeinsamen Geldpolitik zu berücksichtigen. Zudem ermöglicht der Panel-Ansatz, durch Ausnutzung der Querschnittsdimension den Schätzzeitraum auf die Zeit nach der Unterzeichnung des Maastrichter Vertrages zu beschränken. Im Gegensatz zu bisherigen Studien stützt sich die vorliegende Analyse somit nicht auf einen Zeitraum, in dem das geldpolitische Handeln in vielen europäischen Ländern durch den europäischen Wechselkursmechanismus weitgehend beschränkt war.

Die Anwendung von Panel-Schätztechniken liefert plausible Reaktionsfunktionen, die gute Prognoseeigenschaften aufweisen. Insbesondere werden FehlerkorrekturGleichungen ermittelt, die sich durch eine bessere Out-of-Sample Prognosegüte auszeichnen als alternative Reaktionsfunktionen, die auf Grundlage aggregierter Daten geschätzt wurden. Vor allem die Berücksichtigung heterogener Dynamik im Vorfeld der gemeinsamen Geldpolitik scheint die Prognoseeigenschaften dieser Gleichungen zu verbessern.

An einem Beispiel wird der mögliche Einsatz der ermittelten Reaktionsfunktionen zur Analyse von geldpolitischem Handeln nach 1999 veranschaulicht. 


\section{Contents}

1 Introduction 1

2 Historical Reaction Functions for the Euro Area 4

2.1 Related Literature . . . . . . . . . . . . . . . . . . . . . . . 4

2.2 Econometric Specification . . . . . . . . . . . . . 5

2.2.1 Pooled/Fixed-Effects Estimation (SUR) . . . . . . . . . . 5

2.2.2 Pooled Mean Group Estimation . . . . . . . . . . . . . . . . . 8

3 Empirical Results $\quad 10$

$3.1 \quad$ Data . . . . . . . . . . . . . . . . . . . . . 10

3.2 Illustrating Heterogeneity:

Country-Specific Reaction Functions (SUR) . . . . . . . . . . . . 13

3.3 Panel Reaction Functions . . . . . . . . . . . . . . . . . . . 15

3.3.1 Pooled/Fixed-Effects Estimation (SUR): Results . . . . . . . . 15

3.3.2 Pooled Mean Group Estimation: Results . . . . . . . . . . . . . . 17

3.4 Out-of-Sample Forecasts . . . . . . . . . . . . . . . . . . . . 20

3.5 The Importance of National Developments:

A Reverse 'Counterfactual Experiment' . . . . . . . . . . . . . . . . 22

4 Concluding Remarks $\quad 25$

$\begin{array}{lr}\text { References } & 27\end{array}$ 


\section{List of Tables}

1 Panel Unit Root Tests 1993:1-1998:12 . . . . . . . . . . . . . . . . . 12

2 Country-Specific Reaction Functions (SUR) 1993:1-1998:12 . . . . . . . 14

3 Pooled/Fixed-Effects Estimation (SUR) vs. Estimation with Aggregated Data 1993:1-1998:12 . . . . . . . . . . . . . . . . 15

$4 \quad$ Fixed-Effects Estimation (SUR) of Sub-Panels 1993:1-1998:12 . . . . . . 17

$5 \quad$ Pooled Mean Group Estimation 1993:1-1998:12 (Country-Specific) . . . 18

$6 \quad$ Pooled Mean Group Estimation 1993:1-1998:12 (Sub-Panel) . . . . . . . 19

7 Out-of-Sample Forecasts 1999:1-2002:12 (RMSFE) . . . . . . . . 21

8 Out-of-Sample Forecasts: Area-Wide vs. National Data $(R M S F E)$. . . 24

\section{List of Figures}

1 Alternative Measures of Inflationary Expectations (normalized series):

Government Bond Yield vs. Consensus Long-Term Forecasts . . . . . . 11

2 National Divergence in Inflation Rates . . . . . . . . . . . . . 23

3 Implied Interest Rate Paths: Area-Wide vs. National Data . . . . . . 25

A Graphs of the Time Series . . . . . . . . . . . . . . 30 



\section{Interest Rate Reaction Functions for the Euro Area Evidence from Panel Data Analysis ${ }^{1}$}

\section{Introduction}

Understanding interest rate setting in the Euro Area is crucial for evaluating actual European monetary policy. This is why estimating policy reaction functions has gained renewed interest in academic research with Stage Three of the EMU (see e.g. Gerlach and Schnabel 2000; Gerdesmeier and Roffia 2003; Gerlach-Kristen 2003; Adema 2004). In particular, it turns out to be of considerable interest how country-specific interest rate setting in the pre-EMU era relates to actual interest rate setting by the European Central Bank (ECB). This is mainly due to the short time span since the conduct of a single union-wide monetary policy which only allows to draw preliminary conclusions from reaction functions exclusively estimated with data since 1999 (see e.g. Heinemann and Hüfner 2002; Sauer and Sturm 2003; Ullrich 2003).

Intending to relate actual interest rate setting to the historical experience different methodological approaches have been pursued in the literature. First, there are some studies which use aggregated, "synthetic" data for estimating a union-wide reaction function in order to simulate a single monetary policy before 1999 (see e.g. Gerdesmeier and Roffia 2003; Gerlach-Kristen 2003). Second, there are some studies which compare interest rate setting by the German Bundesbank before 1999 with interest rate setting by the ECB afterwards (see e.g. Faust et al. 2001; Smant 2002; Hayo and Hofmann 2003). Overall, these studies show that interest rate setting by the ECB differs from the behavior predicted by a single "Bundesbank rule". In the same spirit, Mihov (2001) argues that interest rate setting in the EMU can better be described by a kind of pooled European policy rule than by a "Bundesbank rule" alone. His study differs from the aforementioned contributions since he draws on a pooled dataset instead of using aggregated data.

\footnotetext{
${ }^{1}$ Author: Karsten Ruth, Goethe-University Frankfurt, Graduate Program "Finance and Monetary Economics", Mertonstr. 17-21, 60054 Frankfurt (Main), Germany; E-mail: ruth@wiwi.uni-frankfurt.de. The research for this paper was conducted while the author was visiting the Economic Research Centre of the Deutsche Bundesbank. I would like to thank the Deutsche Bundesbank, especially Heinz Herrmann, for kind hospitality. I thank Jörg Breitung, Sandra Eickmeier, Ralf Fendel, Heinz Herrmann, Dieter Nautz and Christoph Winter for valuable comments on the paper. Moreover, the paper benefited from discussions with participants of the research seminar at the Deutsche Bundesbank. Needless to say, that all remaining errors are mine. The opinion expressed in this paper does not necessarily reflect the viewpoint of the Deutsche Bundesbank.
} 
This paper adds to the literature by investigating whether the application of panel data techniques to country-specific data before 1999 improves the ability of historical reaction functions to predict Euro Area interest rate setting since 1999. To this aim we estimate union-wide reaction functions up to 1999 based on a panel including (up to) ten actual Member States of the EMU. In contrast to Mihov (2001), we employ alternative estimation techniques to account for both cross-country correlation as well as cross-country heterogeneity. In line with the literature (e.g. Faust et al. 2001; Clausen and Hayo 2002; Smant 2002), we assess the appropriateness of different panel reaction functions by comparing the implied interest rate paths with euro interest rates since 1999. Specifically, we evaluate the out-of-sample forecast performance of the reaction functions against a corresponding reaction function estimated with aggregated, "synthetic" data.

A further contribution of our paper is that we explicitly account for potential nonstationarity of interest rates and inflation detected by panel unit root tests over the sample under regard. Recent empirical research on Taylor-type rules has indicated that reaction functions estimated in levels might suffer from neglecting the non-stationarity of the variables entering the rule (e.g. Österholm 2003; Christensen and Nielsen 2003). For instance, Gerlach-Kristen (2003) found that a traditionally specified Taylor rule for the Euro Area estimated in levels exhibited temporal instability and a bad out-ofsample forecast performance. By contrast, augmented Taylor-type rules retrieved from an error-correction equation did not show signs of misspecification and forecasted well. We build on this research by translating the error-correction approach to the panel framework.

Estimating a historical policy rule for a "fictitious" European central bank within a panel framework might be advantageous for several reasons. First, we circumvent the use of aggregated, "synthetic" data before the conduct of a single monetary policy. Empirical results on union-wide pre-EMU policy rules estimated with aggregated data might suffer from implausible homogeneity restrictions imposed across countries. In fact, estimating a union-wide reaction function with aggregated data restricts all model parameters to be the same for all countries. In contrast, within the panel framework it is possible to account for some cross-country heterogeneity while maintaining the assumption of a common functional form of the policy rule for all countries. It should be emphasized that it is just a particular characteristic of the panel approach that it allows to relax the degree of homogeneity imposed across countries compared to using aggregated data. This makes the panel framework desirable for estimating a union-wide reaction function with data before 1999 . 
Second, by exploiting the cross-section dimension of a multi-country panel we might get more precise estimates of the policy rule parameters while, instantaneously, it is possible to shorten the estimation sample compared to other studies. Starting with estimation in 1993 (after the signing of the Maastricht Treaty) appears to be appropriate in the light of the beginning convergence process towards Stage Three of the EMU. Moreover, by excluding data from the eighties we avoid to assume independent monetary policy by all national authorities for a period which was characterized by a far-reaching lack of monetary independence in most of the European countries due to the asymmetric design of the Exchange Rate Mechanism (ERM). In contrast, assuming a common European reaction function which presumes some monetary autonomy in all European countries turns out to be justified with regard to the widening of the exchange rate bands to $15 \%$ after the ERM crisis in 1992/93 (see Mihov 2001, p. 395). ${ }^{2}$

We find that estimating interest rate reaction functions within a panel framework pays off with regard to predicting short-term nominal interest rates since 1999. In particular, accounting for heterogeneous adjustment and short-run dynamics improves the predictive ability of the estimated reaction functions compared to the estimation with aggregated data. Though we obtain very imprecise parameter estimates for the equation based on "synthetic" data we observe a satisfactory out-of-sample performance relative to the panel alternatives at short forecast horizons. By contrast, almost all panel specifications outperform the equation based on aggregated data at longer horizons. Our preferred reaction function is a Taylor-type policy rule in line with the Taylor-principle while exhibiting a lower output gap coefficient than usually found in the literature. This may be largely due to the inclusion of the long-term bond rate which is argued to capture long-run inflationary expectations. Finally, we demonstrate that the preferred panel reaction function might be a valuable tool for evaluating episodes of monetary policy since 1999 .

The paper is structured as follows. Section 2 gives a brief survey of related literature emphasizing the importance of historical reaction functions for evaluating monetary policy since 1999. Furthermore, the employed estimation approaches are presented and discussed. Section 3 summarizes our empirical results. At first, we will illustrate the existence of cross-country differences by estimating country-specific reaction functions before imposing a higher degree of homogeneity within the panel framework. We evaluate the panel reaction functions by comparing the out-of-sample performance with a reaction function estimated with aggregated data. Furthermore, we use our preferred reaction function for evaluating episodes of monetary policy since 1999. Finally, section 4 concludes.

\footnotetext{
${ }^{2}$ This is also in line with Wesche (2003) who finds for France and Italy that around 1993 there was a switch to a monetary policy regime where the influence of German interest rate policy on domestic policy decisions was no longer dominant.
} 


\section{Historical Reaction Functions for the Euro Area}

\subsection{Related Literature}

In a recent paper Sauer and Sturm (2003) give a systematic survey of research on reaction functions for the Euro Area. They classify three groups of studies. First, there are studies which compare actual interest rate setting by the ECB with the hypothetical path of a "Bundesbank rule" estimated up to 1998 (e.g. Clarida et al. 1998; Faust et al. 2001; Smant 2002). These studies show that interest rate setting since 1999 remarkably deviates from the implied interest rate path retrieved from a historical "Bundesbank rule". ${ }^{3}$ Second, a lot of studies present estimates of reaction functions based on aggregated data for a "hypothetical" Euro Area before 1999 (e.g. Gerlach and Schnabel 2000; Clausen and Hayo 2002). These reaction functions are generally interpreted to reflect a union-wide "average monetary policy" before the launch of the Euro (see Gerdesmeier and Roffia 2003, p. 39). As a key result these studies conclude that Taylor-type policy rules are suitable to serve as a benchmark for understanding and evaluating monetary policy in the Euro Area (see also Peersman and Smets 1999; Taylor 1999). In particular, it is emphasized that there are no indications that monetary policy was subject to a structural break in 1999 (see Clausen and Hayo 2002; GerlachKristen 2003). This finding confirms that insights on interest rate setting from the pre-EMU era are valuable for understanding actual monetary policy.

Finally, there is some recent research on Euro Area reaction functions exclusively based on data since 1999 (e.g. Heinemann and Hüfner 2002; Sauer and Sturm 2003; Ullrich 2003; Fendel and Frenkel 2004). However, these authors are keen to emphasize the preliminary character of their empirical results due to the short time span since the conduct of a single monetary policy. This indicates that, for the time being, there remains the necessity to relate actual interest rate setting to the historical pre-EMU experience.

Apart from the aforementioned contributions there are only two studies which deal with pooled datasets before 1999: in order to increase the number of (annual) observations Wyplosz (1999) estimates various reaction functions based on a panel of eleven European countries within the sample 1982-1997. His results confirm the existence of a systematic relationship between the short-term nominal interest rate, inflation and the output gap in the Euro Area. More directly related to our paper is a study by Mihov (2001) who presents a pooled policy rule estimated on a dataset including data for Germany, France and Italy. He also compares the implied interest rate path with

\footnotetext{
${ }^{3}$ One exception is the study by Surico (2003) who detects similarity between the Bundesbank and the ECB behavior described by a non-linear reaction function.
} 
interest rates since 1999 and concludes that interest rate setting in the Euro Area can better be described by a pooled policy rule building on a "collective experience" than by a "Bundesbank rule" alone.

Our paper seeks to advance on the idea of retrieving additional information from a pooled dataset by facing some of the problems prevalent in the studies above: in contrast to Wyplosz (1999) who estimated a level specification we employ an errorcorrection approach to account for indications of non-stationarity of the variables entering the reaction function over the sample under regard (see Gerlach-Kristen 2003). Furthermore, by excluding data of the eighties we avoid the critical assumption of a common union-wide reaction function for a period when monetary autonomy was severely restricted by the ERM.

Mihov (2001) also chooses the start of his sample period at the beginning of the nineties but he only focuses on three member countries of the EMU. Furthermore, by performing a standard pooled estimation he does not allow for cross-country heterogeneity. In the light of remarkable cross-country differences in economic conditions at the beginning of the convergence process both considering more countries and accounting for country-specific effects appears to be desirable when estimating a reaction function based on panel data.

\subsection{Econometric Specification}

\subsubsection{Pooled/Fixed-Effects Estimation (SUR)}

Traditionally, interest rate rules of the form introduced by Taylor (1993) are estimated in levels. However, the estimated equations often display pronounced serial correlation in the residuals (see Gerlach and Schnabel 2000). This is why one lag of the interest rate is often included as additional regressor (see e.g. Clarida et al. 1998). The highly significant impact of the lagged interest rate is usually interpreted to reflect interest rate smoothing, i.e. the central bank's willingness to adjust interest rates gradually in order to signal continuity of monetary policy to the public.

However, the observed persistence in interest rates might also indicate that interest rates follow (near) unit root processes. For instance, one common characteristic of estimated level specifications supporting this viewpoint is a very large $R^{2}$-value (typically above 0.95) which sharply declines when excluding the lagged interest rate (see Gerdesmeier and Roffia 2003, p. 28). This is why there is a growing literature on Taylor-type policy rules which emphasizes the potential pitfalls of level specifications arising from the non-stationarity of the variables entering the reaction function 
(see e.g. Österholm 2003; Christensen and Nielsen 2003). ${ }^{4}$

In this paper we pursue an error-correction approach to the Taylor rule, following Judd and Rudebusch (1998) as well as Gerlach-Kristen (2003). Dynamic modeling of the Taylor rule within an error-correction framework is desirable for mainly two reasons. First, it allows to account for interest rate smoothing through partial adjustment (Judd and Rudebusch 1998). Second, it allows to avoid potential misspecification arising from neglected non-stationarity of the variables entering the policy rule. This was recently emphasized by Gerlach-Kristen (2003) who proposed to consider Taylor-type policy rules within a cointegration framework. Since panel unit root tests indicate potential non-stationarity of interest rates and inflation over the sample under regard (see section 3.1) accounting for the possibility of cointegration appears to be appropriate. In fact, considering a Taylor-type policy rule as a long-run (equilibrium) relationship is in line with the concept of the target rate. Assuming the target rate to be described by the policy rule, misalignments should be corrected gradually via endogenous changes of the central bank's instrument, i.e. the short-term nominal interest rate. Overall, the error-correction approach provides a very general framework to capture interest rate dynamics. ${ }^{5}$

Augmenting the traditional Taylor rule, Gerlach-Kristen (2003) finds a significant role of the long-term nominal interest rate which is assumed to reflect the public's long-run inflationary expectations. ${ }^{6}$ Including the long-term bond rate in the reaction function in order to capture (long-run) inflationary expectations was also proposed by Mehra (2001) who showed that the explanatory power of Taylor rules estimated for the U.S. increases when including the long rate. Moreover, Goodfriend (1998) already argued that e.g. the U.S. Federal Reserve Bank reacted to movements of the long-term bond rate which were interpreted as changes in the public's inflationary scares. Thus, including the long-term bond rate augments the contemporaneous policy rule by a forward-looking component. ${ }^{7}$

\footnotetext{
${ }^{4}$ Surprisingly, a lot of empirical studies in other research fields - like in the literature on exchange rates or money demand - confirm the non-stationarity of interest rates (see e.g. MacDonald and Taylor 1994) and inflation (see e.g. Coenen and Vega 2001). However, these insights are usually neglected in the literature on policy rules.

${ }^{5}$ In the light of conflicting evidence concerning the integration properties of the variables it should be emphasized that the error-correction approach does not demand the variables to be non-stationary. This is because the error-correction equations - being simple reparametrizations of level specifications are only required to be balanced, see Johnston and DiNardo 1997, chpt.8 and Pesaran et al. 1999, p. 625. For an application of the error-correction approach to the Taylor rule which does not rely on non-stationarity of the variables see Judd and Rudebusch (1998, especially footnote 10).

${ }^{6}$ For a theoretical justification see e.g. Kozicki and Tinsley (2001)

${ }^{7}$ In the same spirit, Surico (2003) uses the 10-year government bond yield as instrument for inflationary expectations.
} 
Specifically, Gerlach-Kristen (2003) identifies a cointegrating relation between the short-term nominal interest rate $(r)$, year-on-year inflation $(\pi)$, the output gap $(y)$ and the long-term nominal interest rate $(l)$ of the form

$$
r_{t}=\theta_{1} \pi_{t}+\theta_{2} y_{t}+\theta_{3} l_{t}
$$

In the spirit of the two-step approach proposed by Engle and Granger (1987), deviations from (1) enter an error-correction equation estimated in a second step as disequilibrium term. Eventually, this error-correction equation is found to exhibit desirable stability and forecasting properties.

In contrast to Gerlach-Kristen (2003), we employ a one-step approach for estimating the long-run relationship (1), following Stock (1987). More specifically, we estimate the following equation: ${ }^{8}$

$$
\begin{aligned}
\Delta r_{i t}= & \alpha_{i}+\phi_{i} r_{i, t-1}+\beta_{1 i} \pi_{i, t-1}+\beta_{2 i} y_{i, t-1}+\beta_{3 i} l_{i, t-1}+\gamma_{i}^{\prime} x_{i t} \\
& +\sum_{j=1}^{p-1} \lambda_{i j}^{*} \Delta r_{i, t-j}+\sum_{j=0}^{q_{1}-1} \delta_{i j}^{*(1)} \Delta \pi_{i, t-j}+\sum_{j=0}^{q_{2}-1} \delta_{i j}^{*(2)} \Delta y_{i, t-j}+\sum_{j=0}^{q_{3}-1} \delta_{i j}^{*(3)} \Delta l_{i, t-j}+\epsilon_{i t} \\
= & \alpha_{i}+\phi_{i}\left(r_{i, t-1}-\theta_{1 i} \pi_{i, t-1}-\theta_{2 i} y_{i, t-1}-\theta_{3 i} l_{i, t-1}\right)+\gamma_{i}^{\prime} x_{i t} \\
& +\sum_{j=1}^{p-1} \lambda_{i j}^{*} \Delta r_{i, t-j}+\sum_{j=0}^{q_{1}-1} \delta_{i j}^{*(1)} \Delta \pi_{i, t-j}+\sum_{j=0}^{q_{2}-1} \delta_{i j}^{*(2)} \Delta y_{i, t-j}+\sum_{j=0}^{q_{3}-1} \delta_{i j}^{*(3)} \Delta l_{i, t-j}+\epsilon_{i t}
\end{aligned}
$$

where $i=1, \ldots, N$ denotes the different cross-section units (i.e. countries) and $t=$ $1, \ldots, T$ captures the time period. $x$ denotes a vector of additional exogenous regressors, e.g. foreign interest rates (see section 3.2), and (lagged) differences of the variables enter the equation to remove potential autocorrelation. Moreover, allowing for very general dynamics by including (lagged) differences we account for potential endogeneity ${ }^{9}$ which allows to estimate (2) by OLS. ${ }^{10}$ Thus, from (2) we retrieve the coefficients of the longrun relation $r_{i t}=\theta_{1 i} \pi_{i t}+\theta_{2 i} y_{i t}+\theta_{3 i} l_{i t}$ as $\theta_{k i}=-\beta_{k i} / \phi_{i}, \forall k=1,2,3$ and $i=1, \ldots, N$.

\footnotetext{
${ }^{8}$ Due to the sufficient number of time series observations $(T=72)$, the bias arising through the lagged dependent variable (Nickell-Bias) can be assumed to be negligible, see Judson and Owen (1999).

${ }^{9}$ However, endogeneity is not likely to be an issue in our context: treating the output gap and inflation as weakly exogenous is widely accepted in the literature on Taylor-type interest rate rules. Moreover, there are empirical studies which show that the impact of anticipated short rate movements on long-term interest rates with maturities of several years is negligible which justifies to treat the bond rate also as exogenous, see e.g. Nautz and Wolters (1999).

${ }^{10}$ OLS estimation of comparable error-correction equations was also performed by Judd and Rudebusch (1998) or Clausen and Meier (2003).
} 
Depending on the degree of imposed homogeneity we can assume different shapes of the parameter vector $\Psi_{i}$ : we can restrict all parameters to be equal across countries (pooled estimation, i.e. $\Psi_{i}=\Psi^{p}$ where $\Psi^{p}=\left[\alpha, \phi, \theta_{k}, \gamma, \lambda_{j}^{*}, \delta_{j}^{*(k)}\right]^{\prime}$ ), we can account for country-specific effects captured by different intercepts (fixed-effects estimation, i.e. $\Psi_{i}=\Psi^{f}$ where $\left.\Psi^{f}=\left[\alpha_{i}, \phi, \theta_{k}, \gamma, \lambda_{j}^{*}, \delta_{j}^{*(k)}\right]^{\prime}\right)$ or we can allow all parameters to differ within a Seemingly Unrelated Regression (SUR) framework (i.e. $\Psi_{i}=\Psi^{S U R}=$ $\left.\left[\alpha_{i}, \phi_{i}, \theta_{k i}, \gamma_{i}, \lambda_{i j}^{*}, \delta_{i j}^{*(k)}\right]^{\prime}\right)$. Note, that in the latter case the SUR approach constitutes a difference to estimating equation (2) separately for each country by OLS. This is because the SUR estimation accounts for cross-country interrelationships (i.e. contemporaneous correlation) even when countries are treated as completely heterogeneous (see section 3.2). ${ }^{11}$

\subsubsection{Pooled Mean Group Estimation}

According to Pesaran et al. (1999), the Pooled Mean Group (PMG) estimation technique for dynamic heterogeneous panels represents an intermediate case between the Mean Group (MG) estimation and the traditional pooled estimation techniques (fixed and random effects). While the MG estimation averages coefficients to obtain means of parameter estimates for heterogeneous cross-section units, the pooled estimation techniques assume overall homogeneity (at least) for the slope coefficients. In contrast, the PMG estimator only imposes homogeneity for a structural long-run relationship which is assumed to exist for all cross-section units. By contrast, the short-run dynamics are allowed to differ across groups. Thus, by only restricting the long-run slope coefficients to be the same across groups the PMG estimator "allows us to estimate this common long-run coefficient without making the less plausible assumption of identical dynamics in each country" (Pesaran et al. 1999, p. 621).

We employ this alternative method since it turns out to be well suited when seeking to estimate a common European policy rule before 1999: on the one hand the long-run homogeneity restrictions establish the assumption of a common structural relationship between interest rates, inflation and the output gap which appears appropriate in the light of structural convergence in advance of the single monetary policy. On the other hand, the adjustment and short-run dynamics remain unrestricted across countries which appears desirable with regard to differences in monetary and economic conditions observed at the beginning of the convergence process. To end up with a common level of interest rates in 1999 one would expect different speeds of adjustment towards

\footnotetext{
${ }^{11}$ The SUR procedure was introduced by Zellner (1962) and is well suited for the analysis of multicountry panels which typically consist of few countries ( $N$ small) which are observed over a longer time span ( $T$ large).
} 
equilibrium across countries, given homogeneous long-run responsiveness to the variables entering the policy rule. This is because countries with a high level of interest rates are forced to re-establish the equilibrium relatively faster than countries which are almost near the common interest rate level.

Starting point for the PMG estimation of the policy rule (1) is an autoregressive distributed lag equation $\left[A R D L\left(\tilde{p}, \tilde{q}_{1}, \tilde{q}_{2}, \tilde{q}_{3}\right)\right]$ of the form:

$$
r_{i t}=\tilde{\alpha}_{i}+\sum_{j=1}^{\tilde{p}} \tilde{\lambda}_{i j} r_{i, t-j}+\sum_{j=0}^{\tilde{q}_{1}} \tilde{\delta}_{i j}^{(1)} \pi_{i, t-j}+\sum_{j=0}^{\tilde{q}_{2}} \tilde{\delta}_{i j}^{(2)} y_{i, t-j}+\sum_{j=0}^{\tilde{q}_{3}} \tilde{\delta}_{i j}^{(3)} l_{i, t-j}+\eta_{i t}
$$

Re-parametrization of (3) yields the error-correction equation: ${ }^{12}$

$$
\begin{aligned}
\Delta r_{i t}= & \tilde{\alpha}_{i}+\tilde{\phi}_{i} r_{i, t-1}+\tilde{\beta}_{1 i} \pi_{i t}+\tilde{\beta}_{2 i} y_{i t}+\tilde{\beta}_{3 i} l_{i t}+\tilde{\gamma}_{i}{ }^{\prime} x_{i t} \\
& +\sum_{j=1}^{\tilde{p}-1} \tilde{\lambda}_{i j}^{*} \Delta r_{i, t-j}+\sum_{j=0}^{\tilde{q}_{1}-1} \tilde{\delta}_{i j}^{*(1)} \Delta \pi_{i, t-j}+\sum_{j=0}^{\tilde{q}_{2}-1} \tilde{\delta}_{i j}^{*(2)} \Delta y_{i, t-j}+\sum_{j=0}^{\tilde{q}_{3}-1} \tilde{\delta}_{i j}^{*(3)} \Delta l_{i, t-j}+\eta_{i t} \\
= & \tilde{\alpha}_{i}+\tilde{\phi}_{i}\left(r_{i, t-1}-\tilde{\theta}_{1 i} \pi_{i t}-\tilde{\theta}_{2 i} y_{i t}-\tilde{\theta}_{3 i} l_{i t}\right)+\tilde{\gamma}_{i}{ }^{\prime} x_{i t} \\
& +\sum_{j=1}^{\tilde{p}-1} \tilde{\lambda}_{i j}^{*} \Delta r_{i, t-j}+\sum_{j=0}^{\tilde{q}_{1}-1} \tilde{\delta}_{i j}^{*(1)} \Delta \pi_{i, t-j}+\sum_{j=0}^{\tilde{q}_{2}-1} \tilde{\delta}_{i j}^{*(2)} \Delta y_{i, t-j}+\sum_{j=0}^{\tilde{q}_{3}-1} \tilde{\delta}_{i j}^{*(3)} \Delta l_{i, t-j}+\eta_{i t}
\end{aligned}
$$

where $\tilde{\phi}_{i}=-\left(1-\sum_{j=1}^{\tilde{p}} \tilde{\lambda}_{i j}\right), \tilde{\beta}_{k i}=\sum_{j=0}^{\tilde{q}_{k}} \tilde{\delta}_{i j}^{(k)}$ and $\tilde{\theta}_{k i}=\left(-\tilde{\beta}_{k i} / \tilde{\phi}_{i}\right) ; k=\{1,2,3\}$.

Assuming the equation in (4) to be stable for all countries we know that all errorcorrection coefficients will be negative, i.e. $\tilde{\phi}_{i}<0, \forall i=1, \ldots, N$. Again, we retrieve the long-run policy rule as:

$$
\begin{aligned}
r_{i t} & =\left(-\tilde{\beta}_{1 i} / \tilde{\phi}_{i}\right) \pi_{i t}+\left(-\tilde{\beta}_{2 i} / \tilde{\phi}_{i}\right) y_{i t}+\left(-\tilde{\beta}_{3 i} / \tilde{\phi}_{i}\right) l_{i t} \\
& =\tilde{\theta}_{1 i} \pi_{i t}+\tilde{\theta}_{2 i} y_{i t}+\tilde{\theta}_{3 i} l_{i t}
\end{aligned}
$$

As mentioned above, the particular characteristic of the PMG estimator is that it restricts the long-run coefficients to be the same across countries; i.e. $\theta_{k i}=\theta_{k}$, $\forall i=1, \ldots, N$ and $k=\{1,2,3\}$, while leaving the adjustment and short-run dynamics

\footnotetext{
${ }^{12}$ Note, that the time indices for $\pi, y$ and $l$ differ compared to equation (2) in order to capture the special case of an $\operatorname{ARDL}(1,0, . ., 0)$ equation. However, this does not harm the interpretation of (4) as error-correction equation; see Pesaran et al. 1999, p. 627.
} 
unrestricted. Thus, by applying the PMG estimation technique we impose a smaller degree of homogeneity across countries compared to a pooled/fixed-effects estimation as discussed in section 2.2.1. ${ }^{13}$

\section{Empirical Results}

\subsection{Data}

We use monthly data within the estimation sample 1993:1-1998:12. The out-of-sample evaluation period is chosen as 1999:1-2002:12. Country-specific data was fetched from the International Financial Statistics (IFS) provided by the International Monetary Fund (IMF). The call money rate (or money market rate with shortest maturity) was chosen as short-term nominal interest rate, while for the long-term nominal interest rate we took the government bond yield. ${ }^{14,15}$

In order to find support for the assumption that the long-term bond rate is a good measure for long-run inflationary expectations we compared the series with an alternative measure taken from survey data. The London-based firm Consensus Economics provides long-term forecasts of inflation. These forecasts summarize the long-term inflation forecasts of several professional forecast institutions by means of an unweighted average. ${ }^{16}$ Unfortunately, Consensus (long-term) Forecasts are only available for a limited number of European countries and for a small sample at semi-annual frequency. Thus, we cannot perform our whole panel estimation with this alternative measure of long-run inflationary expectations. Nevertheless, we can investigate the similarity between both measures for a selected number of countries. Semi-annual observations for the 6-to-10-year inflation forecast ${ }^{17}$ were converted to monthly frequency by linear interpolation. Thus, the survey measure exhibits less variation compared to the long rate by construction. However, visual inspection of the (normalized) series for Germany, France and Italy yields that both series exhibit a remarkably similar downward movement between 1994:1-1998:12. Overall, this might give some further support to the assumption that the long-term bond rate is a valid proxy for capturing long-run inflationary expectations.

\footnotetext{
${ }^{13}$ However, one shortcoming of this approach compared to the approach discussed in section 2.2.1 is the assumption of independent countries with regard to the residual structure. A natural way to deal with cross-country correlation within the PMG framework is to include an additional regressor which impacts all countries, thereby controlling for common effects, see Pesaran et al. 1999, p. 622. We introduce such a global exogenous variable in section 3.2, see also footnote 24 .

${ }^{14}$ Missing observations for Finland (1996:8-1998:10) were added using the respective time series from the OECD statistics.

${ }^{15}$ Graphs of the country-specific time series are shown in Appendix A.

${ }^{16}$ For details on Consensus Economics and its forecasts visit http://www.consensuseconomics.com.

${ }^{17}$ I would like to thank Christina Gerberding and Christian Upper for providing me with the data.
} 
Figure 1: Alternative Measures of Inflationary Expectations (normalized series): Government Bond Yield vs. Consensus Long-Term Forecasts
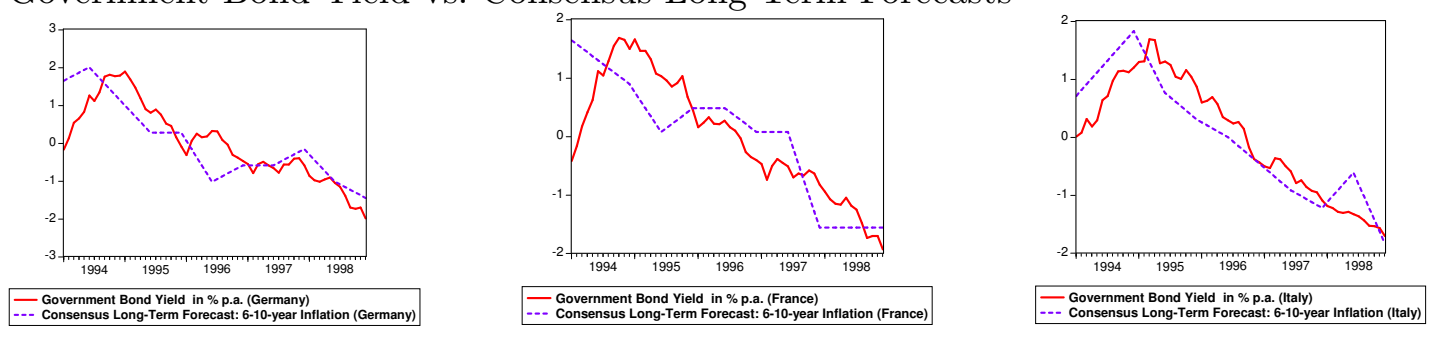

Year-on-year inflation was computed as the annual growth rate of the Consumer Price Index (base year 1995). ${ }^{18}$ In order to construct a measure for the output gap, potential output was calculated applying the Hodrick-Prescott (HP) filter with smoothing parameter $\lambda^{h p}=14400$ to the seasonally adjusted (log) Industrial Production (IP) index series.

In line with Fagan et al. (2001), aggregated European data before 1999 were calculated using 1995 GDP/PPP-weights (rescaled for the omission of Luxembourg). From 1999 onwards we use area-wide variables obtained from the Euro Area Statistics (EAS) provided by the ECB. Inflation was computed as the annual change of the European Harmonized Index of Consumer Prices (HICP) while, again, potential output was calculated applying the HP filter to the (log) IP index. As short-term nominal interest rate we took the EONIA-rate while the 10-year-government bond yield was taken as long-term nominal interest rate.

In order to test for stationarity of the series within the panel framework we applied both the test procedure proposed by Im et al. (2003) (IPS test) and alternatively the test introduced by Levin et al. (2002) (LLC test). ${ }^{19}$

Table 1 reports the test results (based on a common lag length of $m=4) .{ }^{20}$ Interest rates and inflation turn out to be integrated of order one, i.e. $I(1)$, over the sample under consideration while the output gap is stationary by construction. ${ }^{21}$ However, the latter point does not conflict with our estimation approaches as long as interest rates and inflation constitute a (stationary) cointegrating relation which would ensure a balanced regression (see footnote 5 ).

\footnotetext{
${ }^{18}$ Due to data limitations, for Ireland, we took the quarterly CPI series from the OECD statistics and converted it to monthly frequency by quadratic interpolation (averages).

${ }^{19}$ Panel unit root tests were performed using STATA 8.

${ }^{20}$ It is a well-known observation that the test results of (panel) unit root tests can crucially depend on the choice of the lag structure. In fact, over the sample under consideration there is some indication for interest rates and inflation to be near stationary when varying the lag length.

${ }^{21}$ Including a time trend in the (level) test equations for $r, l$ and $\pi$ did not yield qualitatively different results.
} 
Table 1: Panel Unit Root Tests 1993:1-1998:12

\begin{tabular}{||c||c|c||c|c||}
\hline \hline \multicolumn{1}{||c||}{} & \multicolumn{2}{c||}{ IPS test } & \multicolumn{2}{c||}{ LLC test } \\
\hline & level & $1^{\text {st }}$ diff. & level & $1^{s t}$ diff. \\
\hline \hline$\pi$ & $W_{\bar{t}}=-1.18$ & $W_{\bar{t}}=-9.16^{* *}$ & $t^{*}=-1.28$ & $t^{*}=-12.51^{* *}$ \\
$l$ & $W_{\bar{t}}=-0.46$ & $W_{\bar{t}}=-8.81^{* *}$ & $t^{*}=-1.59$ & $t^{*}=-10.79^{* *}$ \\
$r$ & $W_{\bar{t}}=0.39$ & $W_{\bar{t}}=-13.15^{* *}$ & $t^{*}=6.23$ & $t^{*}=-16.07^{* *}$ \\
\hline$y$ & $W_{\bar{t}}=-4.25^{* *}$ & - & $t^{*}=-9.84^{* *}$ & - \\
\hline \hline
\end{tabular}

Notes: $W_{\bar{t}}$ and $t^{*}$ denote the test statistics of the IPS and the LLC unit root test which are both asymptotically standard normally distributed under the null. A constant is included as deterministics for all specifications but the LLC-test on first differences and the output gap. ${ }^{* *}$ denotes significance at the $1 \%$-level.

We applied the residual-based panel cointegration test by Kao (1999) to test for cointegration between the short rate, inflation and the long rate. The test clearly rejects the null of no cointegration with a test statistic of $t_{A D F}=-9.36$. This confirms that there exists a cointegrating relationship between interest rates and inflation.

In order to investigate whether there is potentially more than one cointegrating relation (e.g. a Fisher relation and a term spread) we applied the likelihood-based panel cointegration test by Larsson et al. (2001). This test builds on Johansen's multivariate cointegration rank test by focusing on the standardized mean of individual trace-statistics calculated separately for each cross-section unit. Under the null we observe the same (maximum) cointegration rank $\mathrm{cr}$ for all countries. Since we included a constant as deterministics in the vector error-correction model (VECM) the mean of the country-specific trace-statistics was standardized using the asymptotic values simulated by Breitung (2004). We obtain an (asymptotically standard normally distributed) test statistic of $\Upsilon_{L^{-} R}=5.15$ for the hypothesis $c r=0$ which allows to reject the null of no cointegration at the $1 \%$-level. In contrast, we cannot reject the null of at most one cointegrating relation since we obtain a test statistic of $\Upsilon_{\overline{L R}}^{-}=-0.59$ for $c r \leq 1 .^{22}$ Thus, we find evidence for a cointegration rank of $c r=1$ among interest rates and inflation. ${ }^{23}$

\footnotetext{
${ }^{22}$ These results are based on a lag length (for the VECM) of $\bar{p}-1=4$. Varying the lag length or the formation of the panel did not yield qualitatively different results.

${ }^{23}$ Note, that the fact that there is no indication for a cointegration rank of $\mathrm{cr}=3$ supports our conjecture that the variables are non-stationary over the sample under regard.
} 


\subsection{Illustrating Heterogeneity: Country-Specific Reaction Functions (SUR)}

An illustrative exercise when dealing with the task of cross-country heterogeneity is to estimate, in a first step, country-specific reaction functions based on equation (2). Thereby, we can get an impression about the extent of existing heterogeneity which becomes hidden when imposing a higher degree of homogeneity by performing a pooled/fixed-effects estimation. Specifically, we estimated (2) applying the SUR technique. We included up to six lagged differences to ensure serially uncorrelated residuals in each country-specific equation.

In line with Clarida et al. (1998) or Mihov (2001) we account for the asymmetric design of the ERM by including the German short-term nominal interest rate as additional regressor $x$ in the reaction functions of all European countries but Germany for which we included the U.S. Federal Funds Rate. Thus, this variable can be interpreted to capture the "external constraint" (see Clarida et al. 1998, p. 1046) domestic monetary policy was subject to. ${ }^{24}$ We denote this variable as $r^{e x t}$. Due to the nonstationarity of German and U.S. interest rates detected by conventional ADF-tests (not reported) $r^{e x t}$ enters in first differences (with a time lag of one month). Thus, changes in the domestic policy instrument have two potential sources: domestic economic conditions and changes in a foreign policy instrument. In general, we would assume that the higher the impact of $\Delta r_{t-1}^{e x t}$ the less monetary policy reacted to domestic economic conditions (see Mihov 2001, p. 394).

Table 2 summarizes the results: first, it is noteworthy that the estimated adjustment coefficients $\left(\hat{\phi}_{i}\right)$ are significant for all countries but Spain and France (for which we observe significance at least at the $10 \%$ level) and show the expected negative sign. Moreover, we can observe pronounced differences in the coefficients' magnitude varying between -0.039 (Germany) and -0.322 (Portugal). This confirms our conjecture from above that, in advance of Stage Three of the EMU, we could observe different speeds of adjustment towards the target interest rate across European countries.

Considering the estimates for the coefficients $\theta_{k i}$ it becomes apparent that they are often very imprecise: we only obtain significant estimates for the inflation coefficient of Finland (0.998), Germany (1.094), Italy (0.693) and Portugal (1.119) which are comparable in magnitude with previous empirical findings on Taylor rules (see Sauer and Sturm 2003; p. 10). Nevertheless, the coefficients appear to be slightly below the values usually found in the literature which indicates that by including the long rate

\footnotetext{
${ }^{24}$ By introducing a global variable like the "external constraint"-variable we abandon to include time dummy variables in our estimation.
} 
Table 2: Country-Specific Reaction Functions (SUR) 1993:1-1998:12

\begin{tabular}{||l||c||c|c||c|c||c|c||c||}
\hline \hline Country & $\hat{\phi}_{i}$ & $\hat{\beta}_{1 i}$ & $\hat{\theta}_{1 i}(\pi)$ & $\hat{\beta}_{2 i}$ & $\hat{\theta}_{2 i}(y)$ & $\hat{\beta}_{3 i}$ & $\hat{\theta}_{3 i}(l)$ & $\hat{\gamma}_{i}$ \\
\hline Austria & $-0.090^{* *}$ & 0.043 & 0.477 & 0.005 & 0.050 & 0.001 & 0.012 & $0.442^{* *}$ \\
& 0.020 & 0.035 & 0.357 & 0.007 & 0.085 & 0.028 & 0.315 & 0.133 \\
& $-0.056^{*}$ & 0.001 & 0.018 & -0.003 & -0.060 & -0.017 & -0.304 & -0.587 \\
Netherlands & 0.027 & 0.070 & 1.251 & 0.012 & 0.841 & 0.047 & 0.397 & 0.322 \\
& $-0.043^{* *}$ & 0.057 & 1.347 & $0.017^{*}$ & 0.407 & -0.015 & -0.347 & $0.365^{* *}$ \\
Finland & 0.015 & 0.041 & 0.828 & 0.008 & 0.292 & 0.021 & 0.535 & 0.128 \\
& $-0.132^{* *}$ & $0.132^{* *}$ & $0.998^{* *}$ & $0.024^{*}$ & $0.183^{*}$ & $0.049^{*}$ & $0.132^{* *}$ & 0.202 \\
France & 0.032 & 0.041 & 0.279 & 0.011 & 0.090 & 0.023 & 0.041 & 0.230 \\
& -0.055 & 0.036 & 0.641 & 0.025 & 0.460 & 0.055 & 0.986 & $1.036^{* *}$ \\
Italy & 0.029 & 0.103 & 1.895 & 0.028 & 0.644 & 0.067 & 1.025 & 0.398 \\
Germany & $-0.278^{* *}$ & $0.193^{* *}$ & $0.693^{* *}$ & $0.039^{* *}$ & $0.142^{* *}$ & $0.132^{* *}$ & $0.474^{* *}$ & 0.189 \\
Portugal & 0.047 & 0.047 & 0.156 & 0.015 & 0.054 & 0.034 & 0.079 & 0.296 \\
& $-0.039^{* *}$ & 0.043 & $1.094^{*}$ & $0.034^{* *}$ & 0.879 & -0.025 & -0.629 & -0.178 \\
Spain & 0.019 & 0.026 & 0.468 & 0.009 & 0.500 & 0.022 & 0.738 & 0.097 \\
& $-0.322^{* *}$ & $0.360^{* *}$ & $1.119^{* *}$ & 0.043 & 0.135 & 0.132 & $0.411^{*}$ & 0.023 \\
Ireland & 0.100 & 0.114 & 0.368 & 0.031 & 0.114 & 0.089 & 0.191 & 0.801 \\
& -0.070 & -0.067 & -0.947 & 0.033 & 0.464 & $0.131^{* *}$ & 1.864 & $0.787^{*}$ \\
& 0.039 & 0.071 & 1.209 & 0.022 & 0.525 & 0.049 & 1.351 & 0.398 \\
& $-0.254^{* *}$ & 0.602 & 2.367 & 0.032 & 0.124 & -0.117 & -0.458 & -0.069 \\
\hline
\end{tabular}

Notes: Column 1 denotes the country under regard. Column 2 shows the estimates for the adjustment coefficient $\left(\hat{\phi}_{i}\right)$. Columns 4,6,8 summarize the estimates for the long-run coefficients $\left(\hat{\theta}_{k i}\right)$ which are retrieved from the $\hat{\beta}_{k i}$-coefficients (standard errors for $\hat{\theta}_{k i}$ are computed by the delta method). The last column $\left(\hat{\gamma}_{i}\right)$ reports the estimated coefficients for $\Delta r_{t-1}^{e x t} \cdot{ }^{*}\left({ }^{* *}\right)$ denotes significance at the $5 \%(1 \%)$-level.

in our reaction function we split up the inflation coefficient in a contemporaneous $\left(\theta_{1}\right)$ and a forward-looking part $\left(\theta_{3}\right)$ (see Gerlach-Kristen 2003, p. 15). ${ }^{25}$

This is supported in the three cases where the long-run coefficients for the long rate are significant: adding both coefficients for Finland yields an overall inflation coefficient of $\hat{\theta}_{1}+\hat{\theta}_{3}=0.998+0.373=1.371$, while for Italy we get $0.693+0.474=1.167$ and for Portugal $1.119+0.411=1.530$. With an (overall) inflation coefficient above 1 these reaction functions are in line with the Taylor-principle by indicating that the real rate is raised when inflation increases. ${ }^{26}$ The significant long-run coefficients for the output gap are in a range between 0.142 (Italy) and 0.183 (Finland). Finally, the "external constraint"-variable enters the reaction functions of four countries significantly. Especially the significant influence for Austria and the Netherlands supports the interpretation of the variable since these countries closely tied their interest rate decisions to German monetary policy.

\footnotetext{
${ }^{25}$ This is in line with Christensen and Nielsen (2003, p. 4) who argue that it is the real bond rate which captures "new" information about inflationary expectations. Thereby, the coefficient for the nominal bond rate $\theta_{3}$ captures this "new" information and is subtracted from the "overall" inflation coefficient $\overline{\theta_{1}}$ which would have been estimated without inclusion of the bond rate $l$ :$$
r_{t}=\overline{\theta_{1}} \pi_{t}+\theta_{2} y_{t}+\theta_{3}\left(l_{t}-\pi_{t}\right)=\left(\overline{\theta_{1}}-\theta_{3}\right) \pi_{t}+\theta_{2} y_{t}+\theta_{3} l_{t} .
$$

${ }^{26}$ In the literature on Taylor-type rules the magnitude of the inflation coefficient is typically considered to be "an important yardstick for evaluating a central bank's policy rule" (see Clarida et al. 1998, p. 1037). However, whether an inflation coefficient above 1 in fact implies a stabilizing policy ultimately will depend on the macroeconomic model under regard.
} 
Summarizing, the disaggregate analysis provided empirical results which support plausible reaction functions for some countries. Nevertheless, we are confronted with a lot of very imprecise estimates which may be due to the limited number of observations for each country. This is why in the following we will exploit the cross-section dimension of our multi-country panel by means of a pooled/fixed-effects estimation.

\subsection{Panel Reaction Functions}

\subsubsection{Pooled/Fixed-Effects Estimation (SUR): Results}

We now impose a higher degree of cross-country homogeneity by estimating equation (2) within a pooled/fixed-effects framework. This means that all coefficients are either restricted to be the same across countries (pooled) or that the intercepts are allowed to vary in order to capture country-specific effects while assuming homogeneity of the slope coefficients (fixed-effects), see section 2.2.1.

Again, we started with six lagged differences before removing insignificant lags. In addition to estimating (2) within a pooled/fixed-effects framework (with SUR weighting) we also performed an estimation based on aggregated data (see section 3.1). This allows to detect potential advantages of estimating a historical European reaction function within a panel framework compared to the standard approach of using "synthetic" data. Table 3 summarizes the results: the upper panel shows the results obtained from the pooled, the fixed-effects and the aggregated estimation with the complete set of variables.

Table 3: Pooled/Fixed-Effects Estimation (SUR) vs. Estimation with Aggregated Data 1993:1-1998:12

\begin{tabular}{|c|c|c|c|c|c|c|c|c|}
\hline & $\hat{\phi}$ & $\hat{\beta}_{1}$ & $\hat{\theta}_{1}(\pi)$ & $\hat{\beta}_{2}$ & $\hat{\theta}_{2}(y)$ & $\hat{\beta}_{3}$ & $\hat{\theta}_{3}(l)$ & $\hat{\gamma}$ \\
\hline pooled & $\begin{array}{c}-0.070^{* *} \\
0.008\end{array}$ & $\begin{array}{c}0.041^{* *} \\
0.010\end{array}$ & $\begin{array}{c}0.582^{* *} \\
0.126\end{array}$ & $\begin{array}{c}0.012^{* *} \\
0.004\end{array}$ & $\begin{array}{c}0.165^{*} \\
0.067\end{array}$ & $\begin{array}{c}0.024^{* *} \\
0.009\end{array}$ & $\begin{array}{c}0.338^{* *} \\
0.108\end{array}$ & $\begin{array}{c}0.171^{* *} \\
0.059\end{array}$ \\
\hline fixed-effects & $\begin{array}{c}-0.082^{* *} \\
0.009\end{array}$ & $\begin{array}{c}0.049^{* *} \\
0.013\end{array}$ & $\begin{array}{c}0.594^{* *} \\
0.140\end{array}$ & $\underbrace{0.011^{* *}}_{0.004}$ & $\begin{array}{c}0.139^{*} \\
0.056\end{array}$ & $\begin{array}{c}0.025^{* *} \\
0.010\end{array}$ & $\begin{array}{c}0.299^{*} \\
0.116\end{array}$ & $\begin{array}{c}0.126^{* *} \\
0.063\end{array}$ \\
\hline aggregated & $\begin{array}{c}-0.079^{* *} \\
0.028\end{array}$ & $\begin{array}{c}0.071 \\
0.078 \\
\end{array}$ & $\begin{array}{c}0.894 \\
0.866 \\
\end{array}$ & $\begin{array}{c}0.007 \\
0.018 \\
\end{array}$ & $\begin{array}{c}0.092 \\
0.244 \\
\end{array}$ & $\begin{array}{c}0.024 \\
0.032\end{array}$ & $\begin{array}{c}0.303 \\
0.383 \\
\end{array}$ & $\begin{array}{c}0.456^{* *} \\
0.147\end{array}$ \\
\hline pooled & $\begin{array}{c}-0.059^{* *} \\
0.007\end{array}$ & $\begin{array}{c}0.042^{* *} \\
0.010\end{array}$ & $\begin{array}{c}0.716^{* *} \\
0.137\end{array}$ & $\begin{array}{c}0.015^{* *} \\
0.004\end{array}$ & $\begin{array}{c}0.257^{* *} \\
0.075\end{array}$ & - & - & $\begin{array}{c}0.164^{* *} \\
0.059\end{array}$ \\
\hline fixed-effects & $\begin{array}{c}-0.072^{* *} \\
0.008\end{array}$ & $\begin{array}{c}0.056^{* *} \\
0.013\end{array}$ & $\begin{array}{c}0.773^{* *} \\
0.133\end{array}$ & $\begin{array}{c}0.014^{* *} \\
0.004\end{array}$ & $\begin{array}{c}0.199^{* *} \\
0.060\end{array}$ & - & - & $\begin{array}{c}0.131^{*} \\
0.063\end{array}$ \\
\hline aggregated & $\begin{array}{c}-0.073^{* *} \\
0.027\end{array}$ & $\begin{array}{c}0.104^{*} \\
0.065\end{array}$ & $\begin{array}{c}1.425^{* *} \\
0.488 \\
\end{array}$ & $\begin{array}{c}0.016 \\
0.014\end{array}$ & $\begin{array}{c}0.218 \\
0.224 \\
\end{array}$ & - & - & $\begin{array}{c}0.471^{* *} \\
0.146\end{array}$ \\
\hline
\end{tabular}

Notes: Column 1 denotes the estimation approach under regard. Column 2 shows the estimate for the adjustment coefficient $(\hat{\phi})$. Columns $4,6,8$ summarize the estimates for the long-run coefficients $\left(\hat{\theta}_{k}\right)$ which are retrieved from the $\hat{\beta}_{k}$-coefficients (standard errors for $\hat{\theta}_{k}$ are computed by the delta method). The last column $(\hat{\gamma})$ reports the estimated coefficient for $\Delta r_{t-1}^{e x t}$. The upper and the lower panel differ with regard to the inclusion of the long-term nominal interest rate $l .{ }^{*}\left({ }^{* *}\right)$ denotes significance at the 5\%(1\%)-level. 
We can observe that the results for the pooled and the fixed-effects estimation are very similar. ${ }^{27}$ The estimated adjustment coefficients $(\hat{\phi})$ are significant at the $1 \%$-level and the negative sign confirms the prevalence of an error-correction mechanism. In addition, all long-run coefficients are highly significant and show the expected positive sign. This means that the short-term nominal rate is raised when inflation, the output gap or the long-term nominal rate rises. However, the estimated long-run coefficients are slightly lower than usually found in the literature. In particular, the sum of the coefficients on inflation $\left(\hat{\theta}_{1}\right)$ and the long rate $\left(\hat{\theta}_{3}\right)$ is close but below 1 . The coefficient for the "external constraint"-variable $(\hat{\gamma})$ is estimated significantly positive which confirms that positive changes of this variable also lead to positive changes of the domestic policy instrument. Overall, it becomes apparent that we get very precise estimates from the pooled/fixed-effects estimation. ${ }^{28}$

In contrast, only the adjustment coefficient and the $\gamma$-coefficient turn out to be significant in the estimation with aggregated data. ${ }^{29}$ Nevertheless, the long-run coefficients show the expected positive sign and the magnitude of the inflation and the output coefficient are comparable with previous empirical findings. However, the estimates are very imprecise.

In order to support the argumentation that the single inflation coefficient usually estimated for reaction functions is split up by including the long rate we re-estimated the equations without the long rate. ${ }^{30}$ For the panel estimations the results strikingly support our interpretation: the effect of the long rate almost completely feeds in the inflation and the output coefficient while all other coefficients remain largely unchanged. Considering the fixed-effects results, the sum of the increase in the inflation coefficient (0.179) and the output gap coefficient (0.060) almost equals the estimated long-run coefficient of the long rate from before (0.299). While the bulk feeds in the inflation coefficient the slight increase in $\hat{\theta}_{2}$ is in accordance with the usual interpretation of the output gap as being a leading indicator for future inflation (see Judd and Rudebusch 1998, p. 6).

\footnotetext{
${ }^{27}$ This is in line with an $F$-test $(p=0.42)$ on the joint hypothesis that all country-specific intercept terms are equal to zero.

${ }^{28}$ One exception are the parameter estimates for the constant. Throughout this paper we will not report estimates for the constant which were found to be insignificant. Though we are aware that the constant of Taylor-type rules contains information about the underlying equilibrium real interest rate and/or the inflation target, we argue that it is not possible to reveal valuable information from insignificant estimates, see Gerlach-Kristen (2003, p. 11).

${ }^{29}$ For the estimation with aggregated data we used the U.S. Federal Funds Rate as "external constraint"-variable.

${ }^{30}$ According to the cointegration tests, the inclusion of the long rate is important for the nonstationary variables to be cointegrated. Thus, estimation results without the long rate - although illustrative - should be interpreted with caution.
} 
Finally, we investigated whether our results are sensitive to the formation of the panel by considering results for two sub-panels. It could be argued that, with regard to the panel estimation, the low coefficient on inflation results from the inclusion of countries which did not pursue an active monetary policy. This is why we first excluded Austria, Belgium and the Netherlands from our panel. Furthermore, following Mihov (2001), we also considered a sub-panel consisting of the three largest economies Germany, France and Italy.

Table 4: Fixed-Effects Estimation (SUR) of Sub-Panels 1993:1-1998:12

\begin{tabular}{||l||c||c|c||c|c||c|c||c||}
\hline \hline \multicolumn{1}{|c||}{ Panel } & $\hat{\phi}$ & $\hat{\beta}_{1}$ & $\hat{\theta}_{1}(\pi)$ & $\hat{\beta}_{2}$ & $\hat{\theta}_{2}(y)$ & $\hat{\beta}_{3}$ & $\hat{\theta}_{3}(l)$ & $\hat{\gamma}$ \\
\hline all countries & $\begin{array}{c}-0.082^{* *} \\
0.009\end{array}$ & $\begin{array}{c}0.049^{* *} \\
0.013\end{array}$ & $\begin{array}{c}0.594^{* *} \\
0.140\end{array}$ & $\begin{array}{c}0.011^{* *} \\
0.004\end{array}$ & $\begin{array}{c}0.139^{*} \\
0.056\end{array}$ & $\begin{array}{c}0.025^{* *} \\
0.010\end{array}$ & $\begin{array}{c}0.299^{*} \\
0.116\end{array}$ & $\begin{array}{c}0.126^{* *} \\
0.063\end{array}$ \\
\hline \hline without & $\begin{array}{c}-0.097^{* *} \\
0.011\end{array}$ & $\begin{array}{c}0.089^{* *} \\
0.017\end{array}$ & $\begin{array}{c}0.917^{* *} \\
0.140\end{array}$ & $\begin{array}{c}0.023^{* *} \\
0.006\end{array}$ & $\begin{array}{c}0.238^{* *} \\
0.073\end{array}$ & $\begin{array}{c}0.027^{* *} \\
0.011\end{array}$ & $\begin{array}{c}0.283^{* *} \\
0.107\end{array}$ & $\begin{array}{c}-0.008 \\
0.084\end{array}$ \\
Aut/Bel/Net & & & & & & & & \\
\hline only with & $\begin{array}{c}-0.074^{* *} \\
0.015\end{array}$ & $\begin{array}{c}0.082^{* *} \\
0.024\end{array}$ & $\begin{array}{c}1.112^{* *} \\
0.243\end{array}$ & $\begin{array}{c}0.030^{* *} \\
0.009\end{array}$ & $\begin{array}{c}0.403^{*} \\
0.158\end{array}$ & $\begin{array}{c}0.009 \\
0.015\end{array}$ & $\begin{array}{c}0.127 \\
0.201\end{array}$ & $\begin{array}{c}-0.138 \\
0.098\end{array}$ \\
Ger/Fra/Ita & & & & & & & \\
\hline \hline
\end{tabular}

Notes: Column 1 shows the sub-panel under regard. Column 2 shows the estimate for the adjustment coefficient $(\hat{\phi})$. Columns 4,6,8 summarize the estimates for the long-run coefficients $\left(\hat{\theta}_{k}\right)$ which are retrieved from the $\hat{\beta}_{k}$-coefficients (standard errors for $\hat{\theta}_{k}$ are computed by the delta method). The last column $(\hat{\gamma})$ reports the estimated coefficient for $\Delta r_{t-1}^{e x t}$. Note, that the results in the upper panel are the same as in the second line of Table $3 .{ }^{*}\left({ }^{* *}\right)$ denotes significance at the $5 \%(1 \%)$-level.

Table 4 summarizes the results. In fact, when considering the sub-panel where Austria, Belgium and the Netherlands are omitted, the long-run coefficient for inflation $\left(\hat{\theta}_{1}\right)$ increases. Moreover, the influence of the variable $\Delta r_{t-1}^{e x t}(\hat{\gamma})$ becomes insignificant. These observations are completely consistent with both our assumption that $\Delta r_{t-1}^{e x t}$ captures external constraints on domestic monetary policy as well as the conjecture that the low inflation coefficients reported in Table 3 might be due to the inclusion of countries without active monetary policy. Finally, when only including Germany, France and Italy in the panel, the inflation coefficient further increases. A possible explanation for this observation would be that the reaction function exhibits a stronger reaction to inflation the larger the relative importance of Germany within the panel estimation becomes. However, since the coefficient of the long rate declines and becomes insignificant this interpretation remains vague.

\subsubsection{Pooled Mean Group Estimation: Results}

We proceed by estimating equation (4) applying the PMG estimation technique discussed in section 2.2.2. Note that, in contrast to the procedure above, we now allow both the adjustment dynamics and the short-run dynamics to vary across countries 
while, again, the (long-run) policy rule is restricted to be the same for all countries. The country-specific lag structure was chosen automatically by the Akaike Information Criterion (AIC). Optimization of the log-likelihood function was performed applying the Newton-Raphson-method and using the mean group estimates as initial values. ${ }^{31}$

Table 5: Pooled Mean Group Estimation 1993:1-1998:12 (Country-Specific)

\begin{tabular}{||l||c||c|c|c||c||}
\hline \hline Country & $\hat{\tilde{\phi}}_{i}$ & $\hat{\tilde{\theta}}_{1}(\pi)$ & $\hat{\tilde{\theta}}_{2}(y)$ & $\hat{\tilde{\theta}}_{3}(l)$ & $\hat{\tilde{\gamma}}_{i}$ \\
\hline Austria & $-0.067^{* *}$ & $0.636^{* *}$ & $0.099^{* *}$ & $0.518^{* *}$ & $0.475^{* *}$ \\
& 0.024 & 0.101 & 0.038 & 0.050 & 0.140 \\
& -0.057 & $0.636^{* *}$ & $0.099^{* *}$ & $0.518^{* *}$ & -0.353 \\
Nethium & 0.030 & 0.101 & 0.038 & 0.050 & 0.283 \\
& $-0.059^{* *}$ & $0.636^{* *}$ & $0.099^{* *}$ & $0.518^{* *}$ & $0.450^{* *}$ \\
Finland & 0.018 & 0.101 & 0.038 & 0.050 & 0.134 \\
& $-0.110^{* *}$ & $0.636^{* *}$ & $0.099^{* *}$ & $0.518^{* *}$ & $0.314^{* *}$ \\
France & 0.028 & 0.101 & 0.038 & 0.050 & 0.117 \\
& $-0.104^{* *}$ & $0.636^{* *}$ & $0.099^{* *}$ & $0.518^{* *}$ & 0.291 \\
Italy & 0.030 & 0.101 & 0.038 & 0.050 & 0.362 \\
& $-0.201^{* *}$ & $0.636^{* *}$ & $0.099^{* *}$ & $0.518^{* *}$ & 0.230 \\
Germany & 0.058 & 0.101 & 0.038 & 0.050 & 0.198 \\
& $-0.054^{* *}$ & $0.636^{* *}$ & $0.099^{* *}$ & $0.518^{* *}$ & -0.067 \\
Portugal & 0.019 & 0.101 & 0.038 & 0.050 & 0.198 \\
& $-0.361^{* *}$ & $0.636^{* *}$ & $0.099^{* *}$ & $0.518^{* *}$ & -0.674 \\
Spain & 0.075 & 0.101 & 0.038 & 0.050 & 0.651 \\
& $-0.331^{* *}$ & $0.636^{* *}$ & $0.099^{* *}$ & $0.518^{* *}$ & $0.449^{*}$ \\
Ireland & 0.049 & 0.101 & 0.038 & 0.050 & 0.252 \\
& $-0.109^{* *}$ & $0.636^{* *}$ & $0.099^{* *}$ & $0.518^{* *}$ & 0.418 \\
\hline \hline
\end{tabular}

Notes: Column 1 denotes the country under regard. Column 2 shows the estimates for the adjustment coefficient $\left(\hat{\tilde{\phi}}_{i}\right)$. Column 3-5 summarize the PMG estimates for the (common) long-run coefficients $\left(\hat{\tilde{\theta}}_{k}\right)$. The last column $\left(\hat{\tilde{\gamma}}_{i}\right)$ reports the estimated coefficient for $\Delta r_{t-1}^{\text {ext }}$ (standard errors below coefficients). ${ }^{*}\left({ }^{* *}\right)$ denotes significance at the $5 \%(1 \%)$-level.

Table 5 reports the estimated long-run relationship as well as the country-specific estimation results for the adjustment coefficient $\left(\hat{\tilde{\phi}}_{i}\right)$ and the "external constraint"variable $\Delta r_{t-1}^{e x t}\left(\hat{\tilde{\gamma}}_{i}\right)$. A Hausman test supports homogeneity of the long-run parameters since it is not possible to reject the null of long-run homogeneity $\left(p^{H}=0.34\right)$.

Again, most of the adjustment coefficients are estimated significantly negative, where the coefficient for Belgium is only significant at the $10 \%$-level. ${ }^{32}$ Moreover, magnitude and heterogeneity of the parameter estimates are similar to the estimates obtained from the SUR estimation (see Table 2). Regarding the long-run coefficients we obtain estimates which are similar to the pooled/fixed-effects estimation (see Table 3) although we observe a larger coefficient for the long rate. Joint consideration of the inflation and the long rate coefficient yields an overall inflation coefficient clearly above 1. As sometimes encountered in the literature on Taylor rules the estimated output gap coefficient

\footnotetext{
${ }^{31}$ ML-estimation was carried out using the GAUSS-program written by Y. Shin. The download is available at http://www.econ.cam.ac.uk/faculty/pesaran/public.htm.

${ }^{32}$ This result may be due to marked interest rate changes in Belgium during the ERM crisis in 1993 which we cannot observe for the other countries, see Appendix A.
} 
is very low (see e.g. Faust et al. 2001). Estimates for the "external constraint"-variable $\left(\hat{\tilde{\gamma}}_{i}\right)$ confirm the interpretation of this variable since it significantly enters the reaction functions of Austria and the Netherlands (and additionally of Finland and Spain).

Again, we investigated whether our interpretation of the long rate coefficient as forward-looking component of the (overall) inflation coefficient is justified. Therefore, we excluded the long rate from our estimation (see footnote 30 ). Analogously to Table 3 and 4, Table 6 summarizes the parameter estimates for different sets of variables and sub-panels ${ }^{33}$, where for the adjustment coefficient $(\hat{\tilde{\phi}})$ and the "external constraint"variable $(\hat{\tilde{\gamma}})$ we report the Mean Group (MG)- estimates.

Table 6: Pooled Mean Group Estimation 1993:1-1998:12 (Sub-Panel)

\begin{tabular}{|c|c|c|c|c|c|}
\hline Panel & $\hat{\tilde{\phi}}$ & $\tilde{\tilde{\theta}}_{1}(\pi)$ & $\tilde{\hat{\theta}}_{2}(y)$ & $\tilde{\tilde{\theta}}_{3}(l)$ & $\hat{\tilde{\gamma}}$ \\
\hline all countries & $-0.145^{* *}$ & $\begin{array}{c}0.636^{* *} \\
0.101\end{array}$ & $\begin{array}{c}0.099^{* *} \\
0.038\end{array}$ & $\begin{array}{c}0.518^{* *} \\
0.050\end{array}$ & $\begin{array}{l}0.153 \\
0.124\end{array}$ \\
\hline without Aut/Bel/Net & & $\begin{array}{c}0.641^{* *} \\
0.105\end{array}$ & $\begin{array}{c}0.113^{* *} \\
0.042\end{array}$ & $\begin{array}{c}0.529^{* *} \\
0.052\end{array}$ & $\begin{array}{l}0.151 \\
0.143\end{array}$ \\
\hline all countries & $\begin{array}{c}-0.077^{* *} \\
0.013\end{array}$ & $\begin{array}{c}1.171^{* *} \\
0.107\end{array}$ & $\begin{array}{c}0.377^{* *} \\
0.072\end{array}$ & - & $\begin{array}{l}0.149 \\
0.097\end{array}$ \\
\hline without Aut/Bel/Net & $\begin{array}{c}-0.082^{* *} \\
0.016\end{array}$ & $\begin{array}{c}1.241^{* *} \\
0.126\end{array}$ & $\begin{array}{c}0.486^{* *} \\
0.097\end{array}$ & - & $\begin{array}{r}0.165 \\
0.102 \\
\end{array}$ \\
\hline \multicolumn{6}{|c|}{$\begin{array}{l}\text { Votes: Column } 1 \text { denotes the panel under regard. Column } 2 \text { shows the en } \\
\text { imate for the adjustment coefficient }(\hat{\tilde{\phi}}) \text {. Column } 3-5 \text { summarize the PM } \\
\text { stimates for the (common) long-run coefficients }\left(\tilde{\tilde{\theta}}_{k}\right) \text {. The last column }(\hat{\tilde{\gamma}}) \mathrm{r} \\
\text { orts the estimated coefficient for } \Delta r_{t-1}^{\text {ext }} \text { (standard errors below coefficients } \\
{ }^{2} \text { denotes significance at the } 1 \% \text {-level. }\end{array}$} \\
\hline
\end{tabular}

In fact, when excluding the long rate we obtain reaction coefficients for inflation and the output gap which are directly comparable in magnitude with the estimates usually obtained for Taylor rules (see Sauer and Sturm 2003, p. 10). This is different from our findings within the SUR framework (see Table 3). Furthermore, the exclusion of the long rate changes the magnitude of the adjustment parameter which we also did not observe for the pooled/fixed-effects estimation. Moreover, excluding Austria, Belgium and the Netherlands only marginally changes the estimates for the long-run coefficients.

Thus, the reaction functions estimated within the PMG framework exhibit qualitatively slightly different characteristics compared to the reaction functions obtained from the pooled/fixed-effects estimation: we observe a higher overall speed of adjustment for the estimation with the long rate and no significant impact of the "external constraint"variable. Furthermore, the estimates for the long-run coefficients are largely unaffected by the formation of the panel.

\footnotetext{
${ }^{33}$ We abandon to present less plausible PMG estimation results for a sub-panel including only three countries.
} 
These qualitatively different characteristics may have several causes: within the PMG framework we impose a smaller degree of homogeneity on the dynamics across countries. Simply averaging speeds of adjustment might increase the influence of outliers (e.g. Portugal) compared to the pooled estimation. At the same time, it is one property of the PMG estimator to be robust against outliers with regard to the long-run coefficients (see Pesaran et al. 1999, p. 629).

Overall, the results for the long-run coefficients are very close across the alternative estimation approaches (with the whole set of variables). In contrast, we observe differences for the adjustment coefficient which implies different degrees of interest rate smoothing determined across the approaches. However, which panel approach is more appropriate for describing interest rate dynamics since 1999 remains an empirical question which will be addressed in the next section.

\subsection{Out-of-Sample Forecasts}

In order to evaluate the ability of the panel reaction functions to describe actual interest rate dynamics since 1999 we performed out-of-sample forecasts over the period 1999:1-2002:12. A crucial issue with regard to the forecast comparison is how to achieve comparability between equations, especially with regard to the short-run dynamics. In order to focus on the structural (long-run) relationship, we opted for a parsimonious inclusion of short-run dynamics. In particular, we decided according to the following rule: we only included significant lagged differences of the endogenous variable. Moreover, the "external constraint"-variable $\left(\Delta r_{t-1}^{e x t}\right)$ was always included in the reaction function. ${ }^{34}$ Finally, we omitted the constant which was always estimated insignificantly (see footnote 28). This ensures that forecast improvements are not simply due to intercept shifts but result from equations' different abilities to capture interest rate dynamics.

Table 7 reports Root Mean Squared Forecast Errors $(R M S F E)$ of the alternative error-correction equations. In particular, we focus on the comparison between the panel reaction functions and the reaction function estimated with aggregated data (AGG). We compare the reaction functions for different formations of the panel either including all countries $(\operatorname{PMG}(10) / \operatorname{SUR}(10))$, seven countries $(\operatorname{PMG}(7) / \operatorname{SUR}(7))$ or three countries (SUR(3)). We observe a similar forecast performance of the aggregated equation and the PMG-equations for short-run forecasts (1-/4-months) while the SUR(10)and the SUR(3)-equation are outperformed by the aggregated equation. In terms of the $R M S F E$-criterion, the PMG-equations outperform the aggregated equation from hori-

\footnotetext{
${ }^{34}$ Note, that from 1999 onwards we use the U.S. Federal Funds Rate as "external constraint"-variable.
} 
Table 7: Out-of-Sample Forecasts 1999:1-2002:12 (RMSFE)

\begin{tabular}{||c||l||l|l|l|l|l||}
\hline \hline$h$ & AGG & PMG(10) & PMG(7) & SUR(10) & SUR(7) & SUR(3) \\
\hline 1 & 0.158 & 0.171 & 0.172 & $0.189^{*}$ & 0.179 & $0.210^{*}$ \\
4 & 0.341 & 0.368 & 0.355 & 0.515 & 0.439 & 0.552 \\
8 & 0.630 & 0.518 & 0.485 & 0.858 & 0.695 & 0.899 \\
12 & 0.867 & $0.570^{*}$ & $0.516^{*}$ & 1.100 & 0.850 & 1.117 \\
18 & 1.096 & $0.603^{* *}$ & $0.543^{* *}$ & 1.307 & 0.920 & 1.196 \\
24 & 1.183 & $0.579^{* *}$ & $0.561^{* *}$ & 1.266 & $0.726^{* *}$ & $0.889^{*}$ \\
\hline
\end{tabular}

Notes: Column 1 denotes the forecast horizon under regard. Column 2 shows the $R M S F E$-value for the equation estimated with aggregated data while column 3-4 report the respective results for the PMG-equations for the whole panel and the sub-panel, respectively. Column 5 summarizes the $R M S F E$-results for the SUR estimation with all countries. The last two columns report the results for forecasts of different sub-panel equations (see Table 4$){ }^{*}{ }^{* *}$ ) denotes significance of forecast differences compared to the aggregated equation (AGG) at the 5\%(1\%)-level (Diebold-Mariano-test).

zon $h=8$ onwards. According to the test proposed by Diebold and Mariano (1995) this forecast improvement even becomes significant at $h=12$ where the PMG(7)-equation does slightly better than the PMG(10)-equation. In contrast, the SUR(10)-equation remains outperformed by the aggregated equation over all forecast horizons which also holds for the SUR(3)-equation except for $h=24$. This indicates that, within the SUR framework, neither considering all countries nor focusing on the three largest economies contributes to retrieve a reaction function which captures interest rate dynamics since 1999 appropriately.

However, looking at the SUR(7)-equation, which was estimated after having excluded Austria, Belgium and the Netherlands from the panel, we observe a good forecast performance relative to the aggregated equation: in terms of the RMSFE the SUR(7)-equation performs better from $h=12$ onwards with a significant forecast improvement at $h=24$. In particular, the $\operatorname{SUR}(7)$-equation seems to benefit from the significant impact of the long rate compared to the SUR(3)-equation.

Summarizing, three major points can be retrieved from our forecast comparison: first, the estimation of European reaction functions within a panel framework especially pays off with regard to medium- and long-horizon forecasts. In the short-run we observe a similar performance between the equation based on aggregated data and the preferred panel reaction functions. ${ }^{35}$ Second, equations based on panels including all countries or only three countries are outperformed by equations based on on a panel including seven countries. On the one hand, this seems to confirm the intuition that we cannot retrieve valuable information for simulating a union-wide monetary policy before 1999

\footnotetext{
${ }^{35}$ This might be mainly due to the fact that none of the equations is able to outperform a "naive" random walk forecast significantly for horizons smaller than $h=4$ (not reported).
} 
from countries which did not pursue an active monetary policy. On the other hand, this indicates that we can improve the predictive ability of our reaction functions by considering more than the three largest European economies.

Finally, it is remarkable that error-correction equations obtained from the PMG estimation exhibit the best forecasting properties although the estimate for the output gap coefficient is very small. ${ }^{36}$ This seems to confirm the conjecture that an independent role of the output gap within the reaction function is only justified as long as it contains information about future inflation (see Favero and Rovelli 1999). Since within our specification inflationary expectations are mainly captured by the long rate, the informational content of output gap developments seems to become negligible.

\subsection{The Importance of National Developments: A Reverse 'Counterfactual Experiment'}

A 'counterfactual experiment' often performed in the literature on reaction functions for the Euro Area is to apply a historical policy rule estimated for the German Bundesbank up to 1998 to European data since 1999 (see Clarida et al. 1998; Faust et al. 2001; Smant 2002). The purpose of this exercise is to assess the appropriateness of a single "Bundesbank rule" for describing interest rate setting since 1999 by comparing the implied interest rate path with actual interest rates. Finding that a single "Bundesbank rule" is not appropriate for describing interest rate setting by the ECB is sometimes interpreted as support for the viewpoint that European monetary policy is based on a "collective" rather than a single-country experience (Mihov 2001, p. 395). In a similar fashion we now perform a reverse 'counterfactual experiment': having retrieved an error-correction equation which performs well in describing short-term interest rate dynamics since 1999 (PMG(7)-equation) we apply the area-wide reaction function to country-specific data since 1999. Comparing the implied interest rate paths with the actual EONIA-rate might shed some light on the question whether European monetary policy has potentially reacted to national developments (see also Heinemann and Hüfner 2002; von Hagen and Brückner 2002).

In addition to considering the whole out-of-sample period 1999:1-2002:12 we focus on two characteristic episodes where, for selected countries, we can observe extreme deviations of national inflation from area-wide HICP-inflation (see Figure 2): Portuguese inflation extraordinarily increased compared to area-wide inflation since 2000:3 where the peak was reached in 2001:3 before Portuguese inflation began to decrease. At the

\footnotetext{
${ }^{36}$ The superior forecast performance of the PMG-equations even remains when comparing equations where the short-run dynamics, especially the impact of the U.S. Federal Funds Rate, are excluded.
} 
Figure 2: National Divergence in Inflation Rates
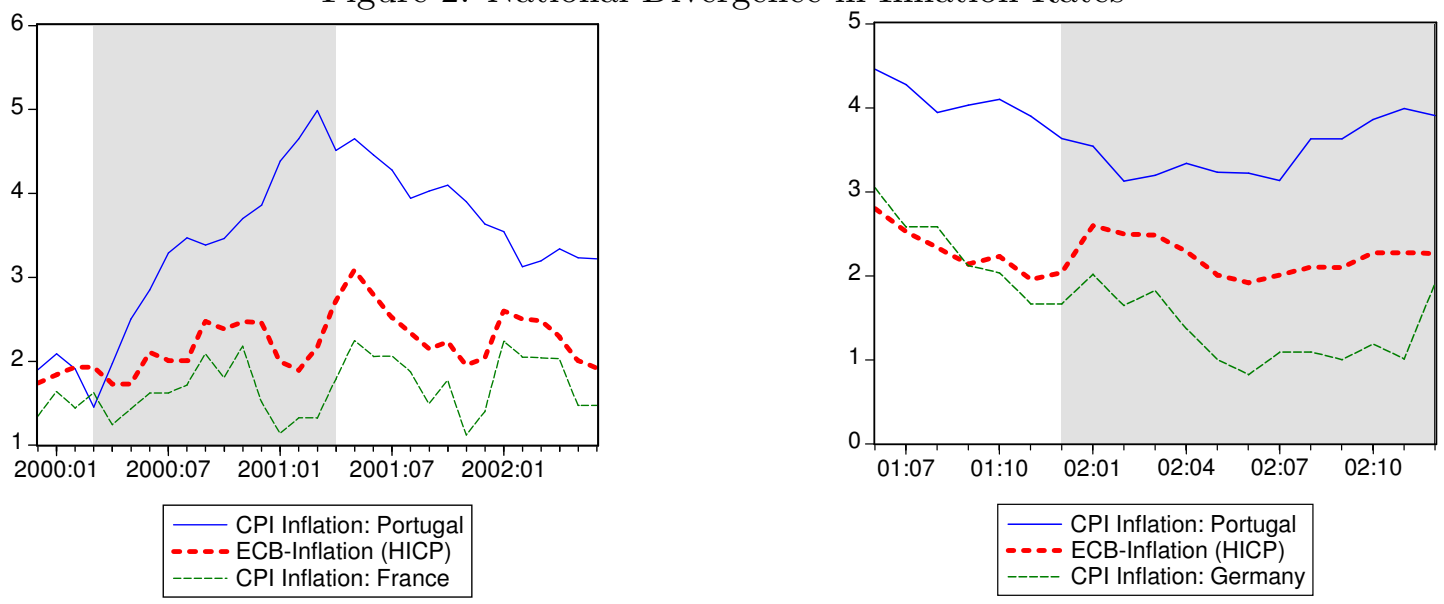

same time, French inflation permanently remained below area-wide inflation. The second episode under regard is the period 2001:12-2002:12 where German inflation substantially remained below while, at the same time, Portuguese inflation was clearly above area-wide inflation. Applying the PMG(7)-panel reaction function to French, German and Portuguese data, respectively, and comparing the implied interest rate paths with the EONIA-rate we will get an impression whether, in the short-run, national developments potentially mattered for interest rate setting. If an equation based on national data outperforms the equation with area-wide data in out-of-sample forecasts this might indicate that interest rate setting was in fact influenced by national developments. ${ }^{37}$ Table 8 reports the $R M S F E$-results for short-run forecasts up to horizon $h=4$.

Some interesting results can be retrieved from the forecast comparison. First, considering the whole sample period there is no indication for an overall national "bias" in interest rate setting: though Portuguese inflation was permanently above area-wide inflation the interest rate path implied when applying the PMG(7)-equation to Portuguese data does (significantly) weaker in describing the EONIA-rate than the path implied when using area-wide data. This also holds for the case when using French data although the differences in forecast accuracy are not significant. Though we observe a slightly better performance when using German rather than area-wide data, we do not

\footnotetext{
${ }^{37}$ We emphasize, that with our exercise we do not claim that monetary policy was conducted in favor of one specific country. In fact, we focus on selected countries since they exhibited extreme developments with regard to the inflation rate. Thereby, these national developments potentially served as indicator for future (area-wide) price developments.
} 
Table 8: Out-of-Sample Forecasts: Area-Wide vs. National Data (RMSFE)

\begin{tabular}{||c||c|c|c|c||c|c|c||c|c|c||}
\hline \hline \multicolumn{1}{||c||}{} & \multicolumn{3}{|c||}{$1999: 1-2002: 12$} & \multicolumn{3}{c||}{$2000: 03-2001: 04$} & \multicolumn{3}{c||}{$2001: 12-2002: 12$} \\
\hline$h$ & AW & Por & Fra & Ger & AW & Por & Fra & AW & Por & Ger \\
\hline 1 & 0.172 & $0.275^{* *}$ & 0.184 & 0.158 & 0.190 & 0.148 & $0.256^{* *}$ & 0.138 & $0.299^{* *}$ & $0.053^{* *}$ \\
2 & 0.242 & $0.470^{* *}$ & 0.266 & $0.206^{*}$ & 0.265 & 0.229 & $0.400^{* *}$ & 0.236 & $0.522^{* *}$ & $0.073^{* *}$ \\
3 & 0.307 & $0.631^{* *}$ & 0.339 & $0.252^{*}$ & 0.356 & 0.284 & $0.543^{* *}$ & 0.322 & $0.701^{* *}$ & $0.092^{* *}$ \\
4 & 0.355 & $0.758^{* *}$ & 0.397 & 0.285 & 0.406 & 0.292 & $0.638^{* *}$ & 0.393 & $0.848^{* *}$ & $0.104^{* *}$ \\
\hline
\end{tabular}

Notes: Column 1 shows the forecast horizon under regard. Columns 2-5 show RMSFE-values based on the PMG(7)-equation applied to area-wide (AW) or national data. Columns 6-8 and 9-11 show the respective results for selected sub-samples. ${ }^{*}\left({ }^{* *}\right)$ denotes significance of forecast differences compared to the area-wide equation (AW) at the 5\%(1\%)-level (Diebold-Mariano-test).

interpret this as an overall national "bias": German and area-wide inflation were very close up to the end of 2001 and significant forecast improvements over the whole period (1999:1-2002:12) are only due to developments in 2002 which will be discussed later. ${ }^{38}$

However, when considering the first episode (2000:3-2001:4) we do remarkably better in describing the EONIA-rate in terms of the RMSFE-criterion when using Portuguese data. Though the differences in forecast accuracy are not significant the interest rate path implied when using Portuguese data is closer to the EONIA-rate. Visual inspection confirms this result: Figure 3 shows that the EONIA-rate was mostly above the (one-step-ahead) interest rate path obtained from area-wide data. In particular, though area-wide inflation decreased in 2001:2 interest rates increased - potentially in order to react to high CPI-inflation in e.g. Portugal ${ }^{39}$ which reached its peak in 2001:3. Consequently, with an EONIA-path lying above the implied area-wide level there is no indication for a French "bias" at all: applying the PMG(7)-equation to area-wide data is significantly better than using French data.

Regarding the second episode (2001:12-2002:12) we obtain a surprising result: the equation with German data clearly outperforms the equation with area-wide data which, in contrast, clearly outperforms the Portuguese equation. This distinct forecast improvement when applying the reaction function to German data within the period under regard is also responsible for the slightly superior "overall" performance detected above. Taken together, this indicates that during this episode European monetary policy potentially was influenced by German price developments though inflation in Portugal was above area-wide inflation.

\footnotetext{
${ }^{38}$ In fact we observe equal forecast accuracy using area-wide and German data when the end of the forecast period is fixed at 2001:12.

${ }^{39}$ Over this period, inflation rates of comparable magnitude could be observed for Spain.
} 
Figure 3: Implied Interest Rate Paths: Area-Wide vs. National Data
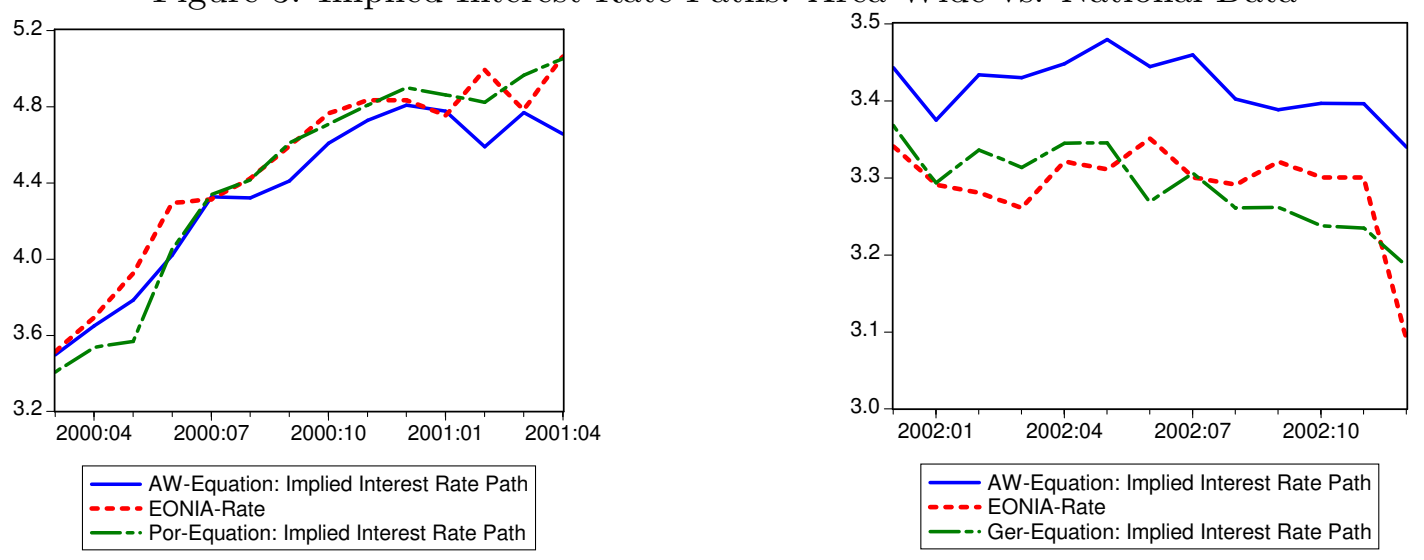

A possible interpretation of our results is that in times of increasing inflationary pressure arising from national developments monetary policy in fact reacted to countryspecific conditions with setting interest rate on a higher level than implied by area-wide inflation. In contrast, without distinct inflationary pressure arising from particular countries interest rates are sometimes even kept below the path implied by area-wide inflation - perhaps fearing deflationary tendencies in some of the Member States. ${ }^{40}$ Overall, the results from our reverse 'counterfactual experiment' may be taken as indication that the ECB potentially used national developments as indicator for inflationary or deflationary tendencies which were - in line with a forward-looking policy - answered with distinct interest rate changes.

\section{Concluding Remarks}

Estimating interest rate reaction functions for the Euro Area is still hampered by the short time span since the conduct of a single monetary policy. In this paper we have shown that estimating a historical interest rate reaction function for the Euro Area within a panel framework is a powerful alternative to the common use of aggregated, "synthetic" data.

In particular, by exploiting the cross-section dimension of a multi-country panel including actual Member States of the EMU we obtained very precise estimates for the coefficients entering the policy rule. Moreover, estimation seems to benefit from accounting for cross-country heterogeneity with regard to adjustment and short-run dynamics in advance of 1999.

\footnotetext{
${ }^{40}$ This is in line with findings of Surico (2003) who describes ECB behavior by a state-dependent, asymmetric reaction function. However, he does not find asymmetric behavior with regard to price developments (inflation/deflation).
} 
Our preferred panel reaction function is a Taylor-type rule in line with the Taylorprinciple. However, we obtain an output gap coefficient which is lower than usually found in the literature. We argue that this is mainly due to the inclusion of the longterm nominal bond rate which is assumed to capture changes in long-run inflationary expectations. According to out-of-sample forecasts the preferred panel reaction function outperforms a corresponding equation estimated with aggregated data, especially at longer forecast horizons.

Overall, our results indicate that as long as time series are considered as too short for building the analysis exclusively on data since 1999 estimating a historical reaction function within a panel framework might be advantageous compared to the use of aggregated, "synthetic" data. 


\section{References}

Adema, Y. (2004). A Taylor Rule for the Euro Area Based on Quasi-Real Time Data. DNB Staff Report No.114/2004, De Nederlandsche Bank.

Breitung, J. (2004). A Parametric Approach to the Estimation of Cointegration Vectors in Panel Data. Working Paper, University of Bonn.

Christensen, A. M. and Nielsen, H. B. (2003). Has US Monetary Policy Followed the Taylor Rule? A Cointegration Analysis 1988-2002. Working Paper 11/2003, Danmarks Nationalbank.

Clarida, R., Galí, J. and Gertler, M. (1998). Monetary Policy Rules in Practice. Some International Evidence. European Economic Review, 42:1033-1067.

Clausen, J. R. and Meier, C.-P. (2003). Did the Bundesbank Follow a Taylor Rule? An Analysis Based on Real-Time Data. Kiel Working Paper No.1180, Kiel Institute for World Economics.

Clausen, V. and Hayo, B. (2002). Monetary Policy in the Euro Area - Lessons from the First Years. Working Paper 02-09, ZEI Bonn.

Coenen, G. and Vega, J.-L. (2001). The Demand for M3 in the Euro Area. Journal of Applied Econometrics, 16:727-748.

Diebold, F. and Mariano, R. (1995). Comparing Predictive Accuracy. Journal of Business and Economic Statistics, 13(3):253-263.

Engle, R. F. and Granger, C. W. J. (1987). Cointegration and Error Correction: Representation, Estimation and Testing. Econometrica, 55:251-276.

Fagan, G., Henry, J. and Mestre, R. (2001). An Area-Wide Model (AWM) for the Euro Area. Working Paper No.42, European Central Bank, Frankfurt / Main.

Faust, J., Rogers, J. and Wright, J. (2001). An Empirical Comparison of Bundesbank and ECB Monetary Policy Rules. International Finance Discussion Paper No. 705, Board of Governors.

Favero, C. A. and Rovelli, R. (1999). Modelling and Identifying Central Banks' Preferences. CEPR Discussion Paper No.2178, Centre for Economic Policy Research, London.

Fendel, R. and Frenkel, M. (2004). Five Years of Single Monetary Policy in Practice: Is the ECB Rule-Based? Working Paper, WHU Koblenz.

Gerdesmeier, D. and Roffia, B. (2003). Empirical Estimates of Reaction Functions for the Euro Area. Working Paper No.206, European Central Bank, Frankfurt / Main. 
Gerlach, S. and Schnabel, G. (2000). The Taylor Rule and Interest Rates in the EMU Area. Economics Letters, 67:165-171.

Gerlach-Kristen, P. (2003). Interest Rate Reaction Functions and the Taylor Rule in the Euro Area. Working Paper No.258, European Central Bank, Frankfurt / Main.

Goodfriend, M. (1998). Using the Term Structure of Interest Rates for Monetary Policy. Federal Reserve Bank of Richmond Economic Quarterly, 84(3):13-30.

Hayo, B. and Hofmann, B. (2003). Monetary Policy Reaction Functions: ECB Versus Bundesbank. Working Paper B24/2003, ZEI Bonn.

Heinemann, F. and Hüfner, F. P. (2002). Is the View from the Eurotower Purely European? National Divergence and ECB Interest Rate Policy. Discussion Paper 02/69, ZEW Mannheim.

Im, K. S., Pesaran, M. H. and Shin, Y. (2003). Testing for Unit Roots in Heterogeneous Panels. Journal of Econometrics, 115:53-74.

Johnston, J. and DiNardo, J. (1997). Econometric Methods. McGraw-Hill, New York, 4th edition.

Judd, J. P. and Rudebusch, G. D. (1998). Taylor's Rule and the Fed: 1970-1997. FRBSF Economic Review, 3:3-16.

Judson, R. A. and Owen, A. L. (1999). Estimating Dynamic Panel Data Models: A Guide for Macroeconomists. Economics Letters, 65:145-150.

Kao, C. (1999). Spurious Regression and Residual-Based Tests for Cointegration in Panel Data. Journal of Econometrics, 90:1-44.

Kozicki, S. and Tinsley, P. A. (2001). Shifting Endpoints in the Term Structure of Interest Rates. Journal of Monetary Economics, 47:613-652.

Larsson, R., Lyhagen, J. and Löthgren, M. (2001). Likelihood-Based Cointegration Tests in Heterogeneous Panels. Econometrics Journal, 4:109-142.

Levin, A., Lin, C.-F. and Chu, C.-S. J. (2002). Unit Root Tests in Panel Data: Asymptotic and Finite-Sample Properties. Journal of Econometrics, 108:1-24.

MacDonald, R. and Taylor, M. (1994). The Monetary Model of the Exchange Rate: Long-Run Relationships, Short Run Dynamics and How to Beat a Random Walk. Journal of International Money and Finance, 13:276-290.

Mehra, Y. P. (2001). The Bond Rate and Estimated Monetary Policy Rules. Journal of Economics and Business, 53:345-358.

Mihov, I. (2001). Monetary Policy Implementation and Transmission in the European Monetary Union. Economic Policy, 16(33):371-406. 
Nautz, D. and Wolters, J. (1999). The Response of Long-Term Interest Rates to News About Monetary Policy Actions: Empirical Evidence for the U.S. and Germany. Weltwirtschaftliches Archiv, 135:397-412.

Österholm, P. (2003). The Taylor Rule: A Spurious Regression? Working Paper 2003-20, Uppsala University, Department of Economics.

Peersman, G. and Smets, F. (1999). A Taylor Rule: A Useful Monetary Benchmark for the Euro Area? International Finance, 2(1):85-116.

Pesaran, M., Shin, Y. and Smith, R. (1999). Pooled Mean Group Estimation of Dynamic Heterogeneous Panels. Journal of the American Statistical Association, 94:621-634.

Sauer, S. and Sturm, J.-E. (2003). Using Taylor Rules to Understand ECB Monetary Policy. Working Paper No.1110, CESifo Munich.

Smant, D. J. (2002). Has the European Central Bank Followed a Bundesbank Policy? Evidence From the Early Years. Kredit und Kapital, 35(3):327-343.

Stock, J. H. (1987). Asymptotic Properties of Least-Squares Estimators of Cointegrating Vectors. Econometrica, 55:1035-1056.

Surico, P. (2003). Asymmetric Reaction Functions for the Euro Area. Oxford Review of Economic Policy, 19(1):44-57.

Taylor, J. B. (1993). Discretion Versus Policy Rules in Practice. Carnegie-Rochester Conference Series on Public Policy, 39:195-214.

Taylor, J. B. (1999). The Robustness and Efficiency of Monetary Policy Rules as Guidelines for Interest Rate Setting by the European Central Bank. Journal of Monetary Economics, 43:655-679.

Ullrich, K. (2003). Comparison Between the Fed and the ECB: Taylor Rules. Discussion Paper No.03-19, ZEW Mannheim.

von Hagen, J. and Brückner, M. (2002). Monetary and Fiscal Policy in the European Monetary Union. IMES Discussion Paper Series, No. 2002-E-16, Bank of Japan.

Wesche, K. (2003). Monetary Policy in Europe: Evidence from Time-Varying Taylor Rules. Bonn Econ Discussion Paper No. 21/2003, University of Bonn.

Wyplosz, C. (1999). Economic Policy Coordination in EMU: Strategies and Institutions. CEPII Document de Travail No.99-04, presented at the Fourth FrancoGerman Forum on Economic Policy Coordination, 11/12 January 1999 Bonn.

Zellner, A. (1962). An Efficient Method of Estimating Seemingly Unrelated Regressions and Test for Aggregation Bias. Journal of the American Statistical Association, $57: 348-368$. 


\section{A Graphs of the Time Series}
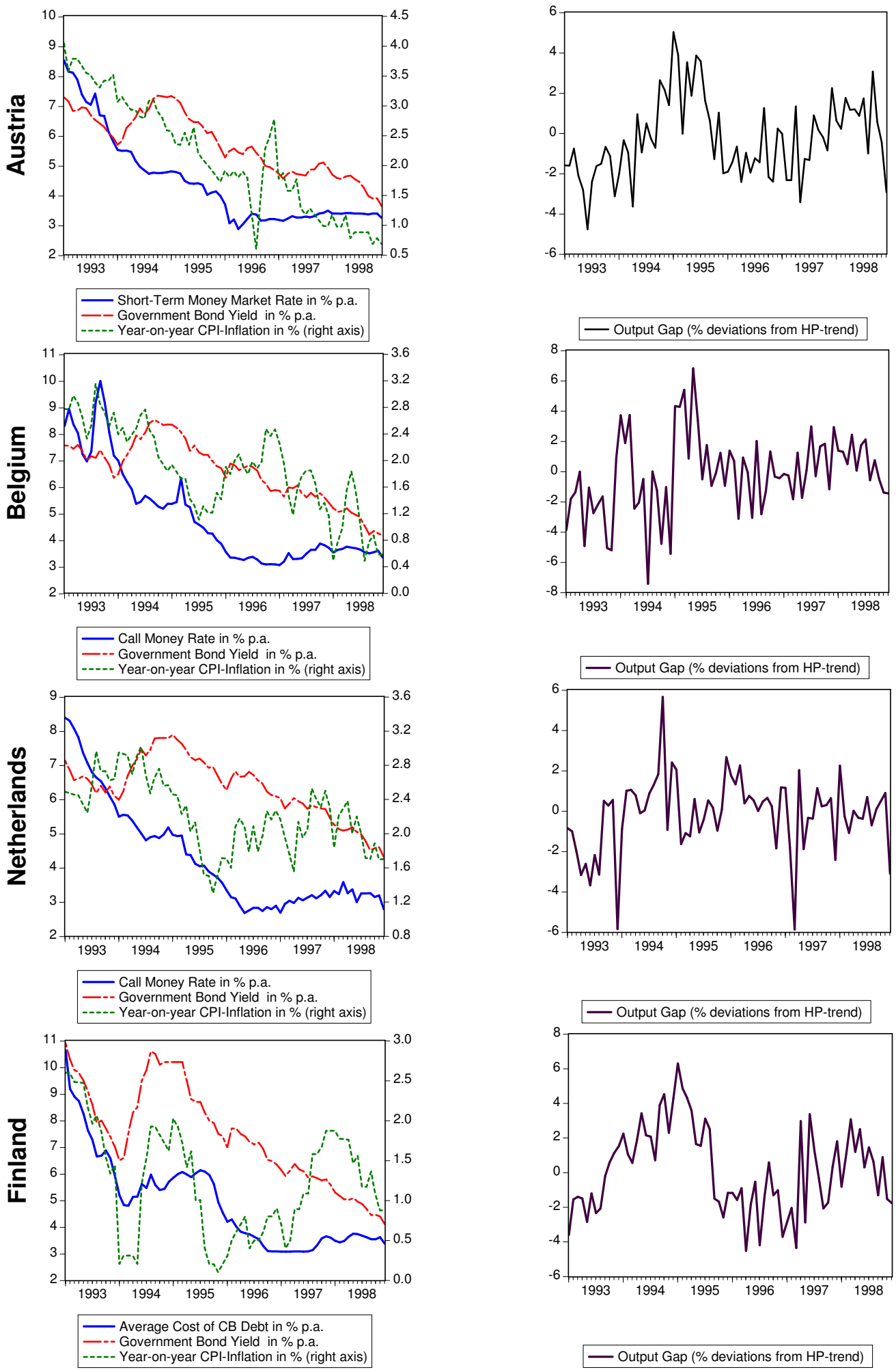

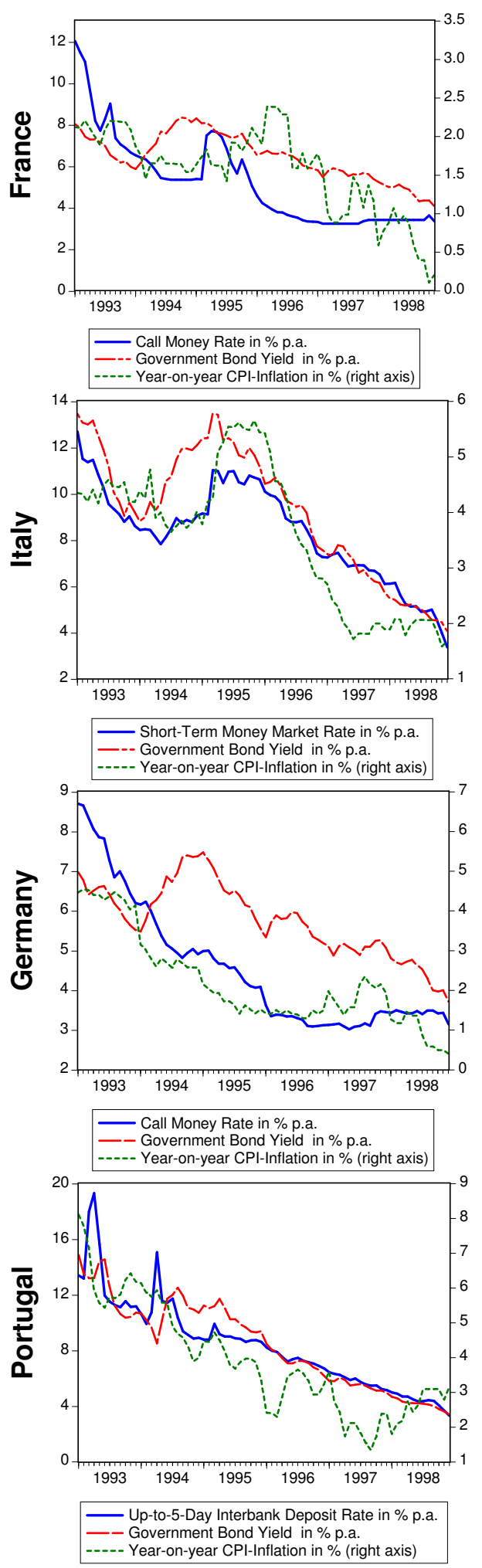
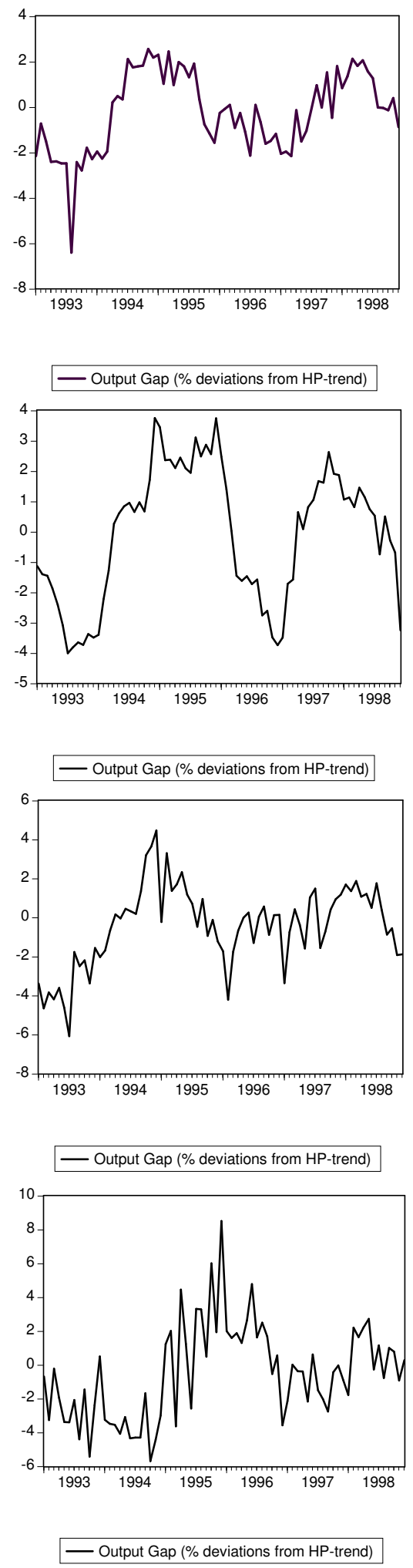

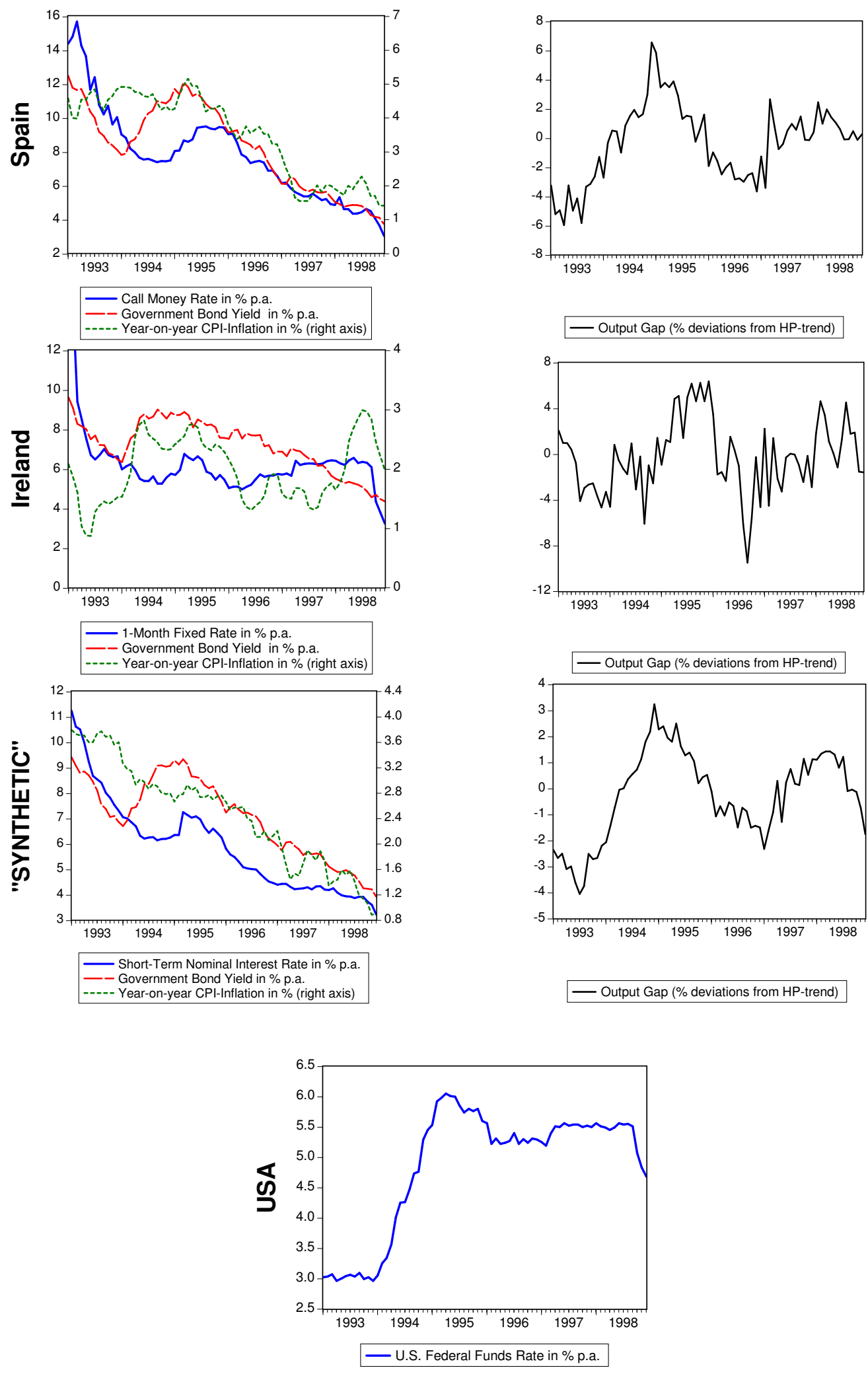


\section{The following Discussion Papers have been published since 2003:}

\section{Series 1: Studies of the Economic Research Centre}

January 2003 Testing mean-variance efficiency in CAPM with possibly non-gaussian errors: an exact simulation-based approach

January 2003 Finite-sample distributions of self-normalized sums

January 2003 The stock return-inflation puzzle and the asymmetric causality in stock returns, inflation and real activity

February 2003 Multiple equilibrium overnight rates in a dynamic interbank market game

February 2003 A comparison of dynamic panel data estimators: Monte Carlo evidence and an application to the investment function

March 2003 A Vectorautoregressive Investment Model (VIM) And Monetary Policy Transmission: Panel Evidence From German Firms

March 2003 The international integration of money markets in the central and east European accession countries: deviations from covered interest parity, capital controls and inefficiencies in the financial sector

March 2003 The international integration of foreign exchange markets in the central and east European accession countries: speculative efficiency, transaction costs and exchange rate premiums
Marie-Claude Beaul Jean-Marie Dufour Lynda Khalaf

Jeong-Ryeol Kim

Jeong-Ryeol Kim

Jens Tapking

Andreas Behr

Joerg Breitung

Robert S. Chirinko

Ulf von Kalckreuth

Sabine Herrmann

Axel Jochem

Sabine Herrmann

Axel Jochem 
Determinants of German FDI:

New Evidence from

Micro-Data

March 2003 On the Stability of

Different Financial Systems

April 2003 Determinants of German Foreign

Direct Investment in Latin American and

Asian Emerging Markets in the 1990s

June 2003 Active monetary policy, passive fiscal

policy and the value of public debt:

some further monetarist arithmetic

June 2003 Bidder Behavior in Repo Auctions

without Minimum Bid Rate:

Evidence from the Bundesbank

June 2003 Did the Bundesbank React to

Stock Price Movements?

152003 Money in a New-Keynesian model

estimated with German data

162003 Exact tests and confidence sets for the

tail coefficient of $\alpha$-stable distributions

172003 The Forecasting Performance of

German Stock Option Densities

182003 How wacky is the DAX? The changing

structure of German stock market volatility
Claudia Buch

Jörn Kleinert

Farid Toubal

Falko Fecht

Torsten Wezel

Leopold von Thadden

Tobias Linzert

Dieter Nautz

Jörg Breitung

Martin T. Bohl

Pierre L. Siklos

Thomas Werner

Jana Kremer

Giovanni Lombardo

Thomas Werner

Jean-Marie Dufour

Jeong-Ryeol Kurz-Kim

B R Craig, E Glatzer,

J Keller, M Scheicher

Jelena Stapf

Thomas Werner 
12004 Foreign Bank Entry into Emerging Economies:

An Empirical Assessment of the Determinants

and Risks Predicated on German FDI Data Torsten Wezel

22004 Does Co-Financing by Multilateral Development

Banks Increase "Risky" Direct Investment in

Emerging Markets? -

Evidence for German Banking FDI Torsten Wezel

32004 Policy Instrument Choice and Non-Coordinated Giovanni Lombardo Monetary Policy in Interdependent Economies Alan Sutherland

$42004 \quad$ Inflation Targeting Rules and Welfare in an Asymmetric Currency Area Giovanni Lombardo

52004 FDI versus cross-border financial services: Claudia M. Buch The globalisation of German banks Alexander Lipponer

$62004 \quad$ Clustering or competition? The foreign Claudia M. Buch investment behaviour of German banks Alexander Lipponer

72004 PPP: a Disaggregated View Christoph Fischer

82004 A rental-equivalence index for owner-occupied Claudia Kurz housing in West Germany 1985 to 1998 Johannes Hoffmann

92004 The Inventory Cycle of the German Economy Thomas A. Knetsch

102004 Evaluating the German Inventory Cycle

Using Data from the Ifo Business Survey Thomas A. Knetsch

$112004 \quad$ Real-time data and business cycle analysis in Germany Jörg Döpke

122004 Business Cycle Transmission from the US to Germany - a Structural Factor Approach Sandra Eickmeier 
132004 Consumption Smoothing Across States and Time: George M.

International Insurance vs. Foreign Loans von Furstenberg

142004 Real-Time Estimation of the Output Gap

in Japan and its Usefulness for

Inflation Forecasting and Policymaking Koichiro Kamada

152004 Welfare Implications of the Design of a

Currency Union in Case of Member Countries

of Different Sizes and Output Persistence Rainer Frey

162004 On the decision to go public: Ekkehart Boehmer

Evidence from privately-held firms Alexander Ljungqvist

$172004 \quad$ Who do you trust while bubbles grow and blow?

A comparative analysis of the explanatory power

of accounting and patent information for the

Fred Ramb

market values of German firms

Markus Reitzig

182004 The Economic Impact of Venture Capital

Astrid Romain, Bruno

van Pottelsberghe

192004 The Determinants of Venture Capital:

Astrid Romain, Bruno

Additional Evidence

van Pottelsberghe

$202004 \quad$ Financial constraints for investors and the

speed of adaption: Are innovators special? Ulf von Kalckreuth

$212004 \quad$ How effective are automatic stabilisers?

Theory and results for Germany and other Michael Scharnagl

OECD countries

Karl-Heinz Tödter

2004 Asset Prices in Taylor Rules: Specification,

Pierre L. Siklos

Estimation, and Policy Implications for the

Thomas Werner

ECB

Martin T. Bohl 
$23 \quad 2004 \quad$ Financial Liberalization and Business

Cycles: The Experience of Countries in

Lúcio Vinhas

the Baltics and Central Eastern Europe

de Souza

242004 Towards a Joint Characterization of

Monetary Policy and the Dynamics of

the Term Structure of Interest Rates

Ralf Fendel

$252004 \quad$ How the Bundesbank really conducted

monetary policy: An analysis based on

real-time data

Christina Gerberding

Andreas Worms

Franz Seitz

262004 Real-time Data for Norway:

T. Bernhardsen, Ø. Eitrheim,

Challenges for Monetary Policy

A.S. Jore, Ø. Røisland

272004 Do Consumer Confidence Indexes Help

Forecast Consumer Spending in Real Time? Dean Croushore

282004 The use of real time information in

Maritta Paloviita

Phillips curve relationships for the euro area

David Mayes

292004 The reliability of Canadian output

Jean-Philippe Cayen

gap estimates

Simon van Norden

$30 \quad 2004 \quad$ Forecast quality and simple instrument rules -

a real-time data approach

Heinz Glück

Stefan P. Schleicher

$312004 \quad$ Measurement errors in GDP and

Peter Kugler

forward-looking monetary policy:

Thomas J. Jordan

The Swiss case

Carlos Lenz

Marcel R. Savioz

$32 \quad 2004 \quad$ Estimating Equilibrium Real Interest Rates

Todd E. Clark

in Real Time

Sharon Kozicki

$33 \quad 2004 \quad$ Interest rate reaction functions for the euro area Evidence from panel data analysis

Karsten Ruth 


\section{Series 2: Banking and Financial Supervision}

$12003 \quad$ Measuring the Discriminative Power

B. Engelmann,

of Rating Systems

E. Hayden, D. Tasche

22003 Credit Risk Factor Modeling and

A. Hamerle,

the Basel II IRB Approach

T. Liebig, D. Rösch

$12004 \quad$ Forecasting Credit Portfolio Risk

A. Hamerle,

T. Liebig, H. Scheule

22004 Systematic Risk in Recovery Rates -

An Empirical Analysis of US Corporate

Credit Exposures

\section{Klaus Düllmann \\ Monika Trapp}

32004 Does capital regulation matter for bank

Frank Heid

behaviour? Evidence for German savings

Daniel Porath

banks

Stéphanie Stolz

$42004 \quad$ German bank lending during

F. Heid, T. Nestmann, emerging market crises:

B. Weder di Mauro,

A bank level analysis

N. von Westernhagen

$52004 \quad$ How will Basel II affect bank lending to

T. Liebig, D. Porath, emerging markets? An analysis based on

B. Weder di Mauro,

German bank level data

M. Wedow 


\section{Visiting researcher at the Deutsche Bundesbank}

The Deutsche Bundesbank in Frankfurt is looking for a visiting researcher. Visitors should prepare a research project during their stay at the Bundesbank. Candidates must hold a $\mathrm{Ph} \mathrm{D}$ and be engaged in the field of either macroeconomics and monetary economics, financial markets or international economics. Proposed research projects should be from these fields. The visiting term will be from 3 to 6 months. Salary is commensurate with experience.

Applicants are requested to send a $\mathrm{CV}$, copies of recent papers, letters of reference and a proposal for a research project to:

Deutsche Bundesbank

Personalabteilung

Wilhelm-Epstein-Str. 14

D - 60431 Frankfurt

GERMANY 
